\title{
Ultrahigh Vacuum and Electrocatalysis - The Powers of Quantitative Surface Imaging
}

Michael Mercer and Harry Hoster, Lancaster University

\begin{abstract}
We highlight the impact of Ultrahigh Vacuum (UHV)-born surface science on modern electrocatalysis. The microscopic, atomic level picture of surface adsorption and reaction, which was developed in the surface science community in decades of systematic research on single crystals in UHV, has meanwhile become state-of-the-art also in electrochemistry. For the example of CO on Pt(111) single crystals, which has been extensively studied at the solid/gas and the solid/liquid interface using atomic resolution scanning tunnelling microscopy (STM), we highlight how both interfaces may have even more in common than often assumed. We then illustrate how planar model surfaces such as mono- and bimetallic single crystals and surface alloys, prepared and thoroughly analysed in UHV, enabled a systematic search for improved electrocatalysts. Surface alloys, thermodynamically more stable than foreign metal islands, are a particularly important subgroup of model surfaces, which so far have only been fabricated in UHV.
\end{abstract}

We also flag that model surfaces may not always assume the structure anticipated for the respective experiment, regardless of their preparation in UHV or by electrochemical methods. "Accidental" surface alloying may be more common than often assumed, leading to misinterpretations of the structure-property relationships targeted in many model studies. We highlight that controlled surface alloy formation should be a key step in any model study looking at bimetallic systems in order to get an idea what the effect of unintended alloying could possibly be, and to cross-check whether alloyed surfaces may potentially be the better electrocatalysts in the first place.

\section{Introduction}

Surface science under vacuum conditions pioneered the research on adsorption and reaction at solid surfaces; these phenomena are monitored by an ever increasing pool of spectroscopic, diffraction, and imaging techniques. A microscopic picture of adsorption and reaction, including the local structure and chemistry of the involved surface, was developed in that community. In electrocatalysis, the accuracy of the microscopic picture quickly advanced once experiments at welldefined single crystals became possible. Those crystals initially had to be prepared in UHV $[1,2]$, but 
methods of fabricating well-oriented single crystals through flame annealing soon became dominant [3]. UHV-based surface analysis instruments paved the way for chemical and structural insights into electrocatalytically relevant adlayers. Hubbard's and Yeager's groups pioneered those ex-situ experiments that relied on a clean transfer from an electrochemical compartment into a UHV chamber [4-8][9][10]. Meanwhile, the portfolio of in-situ imaging and spectroscopy methods grew to an extent that made many ex-situ methods redundant. However, we will highlight that certain irreversible changes in the (non-periodic) surface morphology, under influence of the electrochemical potential, require high-resolution microscopy that so far is still most easily performed ex-situ and in UHV.

This paper will focus on the relevance of UHV for the research on the structural and chemical optimization of bimetallic electrocatalysts. As in heterogeneous catalysis [11-14], the intermixing of various metals is systematically utilized to improve the electrocatalytic activity of electrodes $[7,15-$ 17]. In a systematic optimization strategy, the interplay of a number of electronic and geometric effects must be understood and considered. For instance, variations in the local adsorption properties due to changes in the electronic structure, which often result from compression or expansion of the crystal lattice (strain effects)[18-24] or from the intermetallic bonds in the (near-)surface region (ligand effects) $[12,25]$ need to be considered. Another key factor is the space requirement for adsorbed species during the distinct elementary steps of surface reactions, which is referred to as the geometric ensemble effect [12,25-27]. Reaction paths requiring more space for adsorbed reactants or intermediates can be suppressed by mixtures of active and inactive metals, thus increasing the selectivity towards those pathways that require less space. Apart from the adsorption properties for individual species, many reactions require sites for two different reactants in direct vicinity, e.g., for a Langmuir-type reaction mechanism. On a bimetallic surface, the different reactants may be specifically stabilized by different sites (bifunctional mechanism). On real bimetallic surfaces, these effects usually occur simultaneously. In recent years, advances in theoretical and experimental methods have increasingly improved the molecular scale understanding of the separate phenomena themselves and also their interplay. 


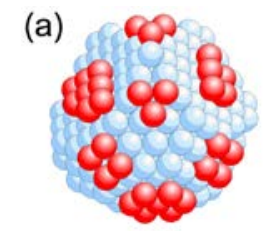

(d)

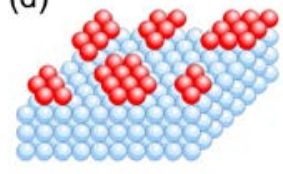

(g)

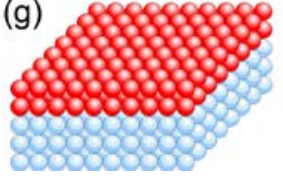

(b)

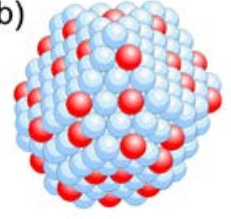

(e)

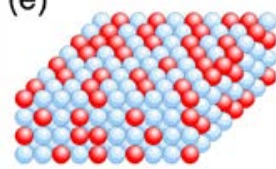

(h)

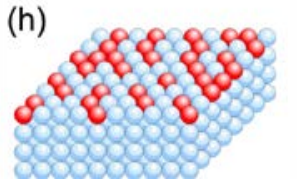

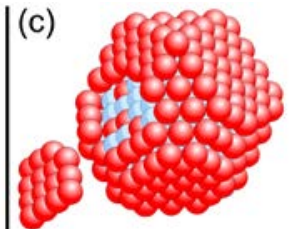

(f)

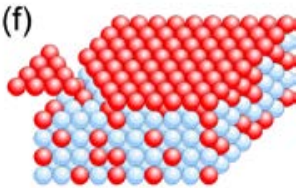

(i)

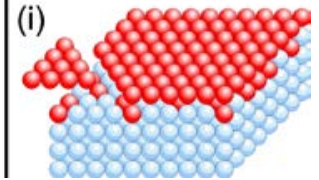

Figure 1-1. Bimetallic nanoparticles (a-c) and corresponding planar model systems (d-i).

Though technically applicable electrocatalysts usually consist of small particles, many important insights are derived in studies at planar model systems $[13,16,25,28,29,30]$. Three generic types of bimetallic particles and corresponding planar model systems are assembled in Figure 1-1. Foreign metal modified nanoparticles (Figure 1-1a) can be modelled by metal single crystals covered by islands (Figure 1-1d) or thicker films (Figure 1-1g) of the respective foreign metal [31]. Alloy particles are often represented by corresponding bulk alloys [32-36] or by thin surface alloys [29,37-39]. Many bimetallic particles are (deliberately) enriched in one component at their surface ("core-shell" particles, see (Figure 1-1c), which in model studies can be mimicked by foreign metal films on bulk alloys (Figure 1-1f) or (sub-)surface alloys (Figure 1-1i).

Optimization of the electrodes through chemical and structural modification demands a certain degree of understanding of the respective reactions at chemically and structurally homogeneous surfaces. Many important lessons are still learned by coordinated modelling and experiments at seemingly simple model systems such as the oxidation/evolution of hydrogen or oxygen, or the oxidation of carbon monoxide on monometallic single crystals. Platinum and ruthenium single crystals turned out to be excellent starting points, not only because these two elements and their alloys were known as powerful fuel-cell electrocatalysts, but also because their adsorption properties for key species like $\mathrm{H}, \mathrm{O}, \mathrm{CO}$ were known from decades of intensive surface science research under UHV conditions [7,40-43]. These surface science insights are essential for the microscopic picture of adsorption and reaction at the solid/liquid interface.

This paper is organized as follows. We will first take a look at a model adsorption system that was studied in depth at the solid/gas and the solid/liquid interface: CO on Pt(111). We will highlight 
how improved experimental approaches made some initially expected discrepancies between both interfaces become less significant. We will then demonstrate how the fabrication and characterisation of model surfaces using UHV based techniques became an essential tool for the collaboration between theory and experiment. This will also involve some selected results of electrochemical studies at UHV prepared surfaces, specifically, $\mathrm{Pt}_{3} \mathrm{Sn}, \mathrm{Pt}$ modified $\mathrm{Ru}$, and $\mathrm{PtRu}$ surface alloys. Those studies involved adsorption and reaction under well-defined electrochemical conditions. In the last section, we will discuss the fact that even very well-defined model surfaces may undergo structural changes when exposed to certain electrochemical potentials. This results in some amendments to the "best practises" of experimental studies on bimetallic model surfaces.

\section{Adlayers at the solid/gas and the solid/liquid interface: CO on $\operatorname{Pt}(111)$}

$\mathrm{CO}$ electro-oxidation is a reaction relevant in electrocatalysis. There are $\mathrm{CO}$ impurities present in the $\mathrm{H}_{2}$ feedstock for application in hydrogen fuel cells, if the feed is produced from hydrocarbons $[44,45]$. CO is also a poisoning species produced during the oxidation of small organic molecules, such as formic acid and methanol $[46,47]$. That motivated a lot of research on $\mathrm{CO}$ adsorption and electrooxidation at smooth model electrodes such as polycrystalline Pt or various Pt single crystal surfaces [7,48-51]. Just for the Pt(111) surface, there are numerous in-depth studies using scanning probe [52-55], spectroscopic [56-59], theoretical [60-63] and electrochemical techniques [7,64-66].

At the solid/gas interface, the interaction of $\mathrm{CO}$ with catalytically active metal surfaces is of interest, too, e.g., CO oxidation [67] and poisoning during ethylene hydrogenation [68] are important reactions. This gave rise to numerous model studies at single crystal surfaces $[24,69,70]$, including also $\mathrm{Pt}(111)[53,71,72]$.

In the following, we will highlight some selected studies on densely packed $\mathrm{CO}$ adlayers on $\mathrm{Pt}(111)$ at the solid/gas and the solid/liquid interface to highlight the parallels and differences between both environments. Historically, gas phase adsorption/desorption studies of CO in UHV at low temperature preceded electrochemical studies. A frequently observed pattern formed by $\mathrm{CO}$ adsorption on $\mathrm{Pt}(111)$ is the $\mathrm{c}(4 \times 2)$ adlayer (see Figure $2-1 \mathrm{a})$, with a $\mathrm{CO}$ coverage of $\theta=0.5$ Monolayer ( $M L ; 1 \mathrm{ML}=1$ adsorbate per surface atom) [8,55,61]. At higher coverages, unit stripes of the $c(4 \times 2)$ adlayer structure, separated by domain walls of a higher local packing density are observed $[8,61]$. However, the relevance of these structures to real catalytic [73], and particularly electrocatalytic $[54,65]$, processes has been questioned. This is not only due to the pressure difference between UHV and real catalytic processes, but it has also been appreciated that the effect of solvent 
coadsorption, as well as the lower surface potentials that typify aqueous electrochemical environments [65], lead to a difference between UHV and electrochemical $\mathrm{CO}$ adlayer structures.

That view changed, when the $\mathrm{CO} / \mathrm{Pt}(111)$ adsorption isotherm was studied by scanning tunneling microscopy (STM) at CO pressures between near-vacuum conditions up to nearly atmospheric pressure [53] ("high-pressure STM" [41], see also the "pressure gap" discussion [73]). Figure 2-1 shows STM images for three different CO pressures $(a, b, c)$, along with the resulting STMbased adsorption isotherm $(d)$. The $c(4 \times 2)$ pattern (Figure 2-1a) obtained at equilibrium with $\mathrm{p}_{\mathrm{co}}=$ $10^{-8}$ Torr is identical to the one obtained by adsorption at low temperatures [55,61]. At higher pressures, more densely packed adlayers appear that get seemingly saturated at $\theta=0.68 \mathrm{ML}$ for $\mathrm{p}_{\mathrm{cO}}$ $=720$ Torr. Those adlayers are laterally compressed and rotated with respect to the substrate, resulting in the Moiré fringes visible in Figure 2-1b and Figure 2-1c. These patterns correspond to an (probably) incommensurate $\left(\theta=0.6 \mathrm{ML}, \mathrm{p}_{\mathrm{CO}}=10^{-2} \mathrm{Torr}\right)$, and $(\sqrt{19} \times \sqrt{19}) \mathrm{R} 23.4^{\circ}-13 \mathrm{CO}(\theta=0.68$ $\mathrm{ML}$ ) structure, respectively. The structures involve part of the $\mathrm{CO}$ molecules occupying adsorption sites other than the three most stable ones (top, bridge, threefold-hollow [60]). That is possible when on average the energy gained by adsorbing more CO surpasses the energy loss due to the occupation of less favourable adsorption sites.

It has been emphasized that the effect of raising the pressure is equivalent to lowering the temperature, provided that thermodynamic equilibrium remains kinetically accessible [74]. In that picture, the formation of the more densely packed adlayers (Figure 2-1 b\&c) at lower temperatures may be hindered by a lack of thermal fluctuations in the adlayer. Such fluctuations are necessary to provide space for further adsorption, but they require the adoption of energetically less favourable adsorption sites by the $\mathrm{CO}$ adsorbates. In turn, the less stable adsorption sites that $\mathrm{CO}$ is forced to occupy at higher coverage, in combination with adsorbate-adsorbate repulsions, makes the adsorbed $\mathrm{CO}$ less stable against $\mathrm{CO}_{2}$ formation by reaction with $\mathrm{O}_{\text {ad }}$ and may thus be the essential element of reactive $\mathrm{CO}$ adlayers (Brønstedt-Polanyi-Evans relation $[75,76])$. 
(a)

(b)

(c)

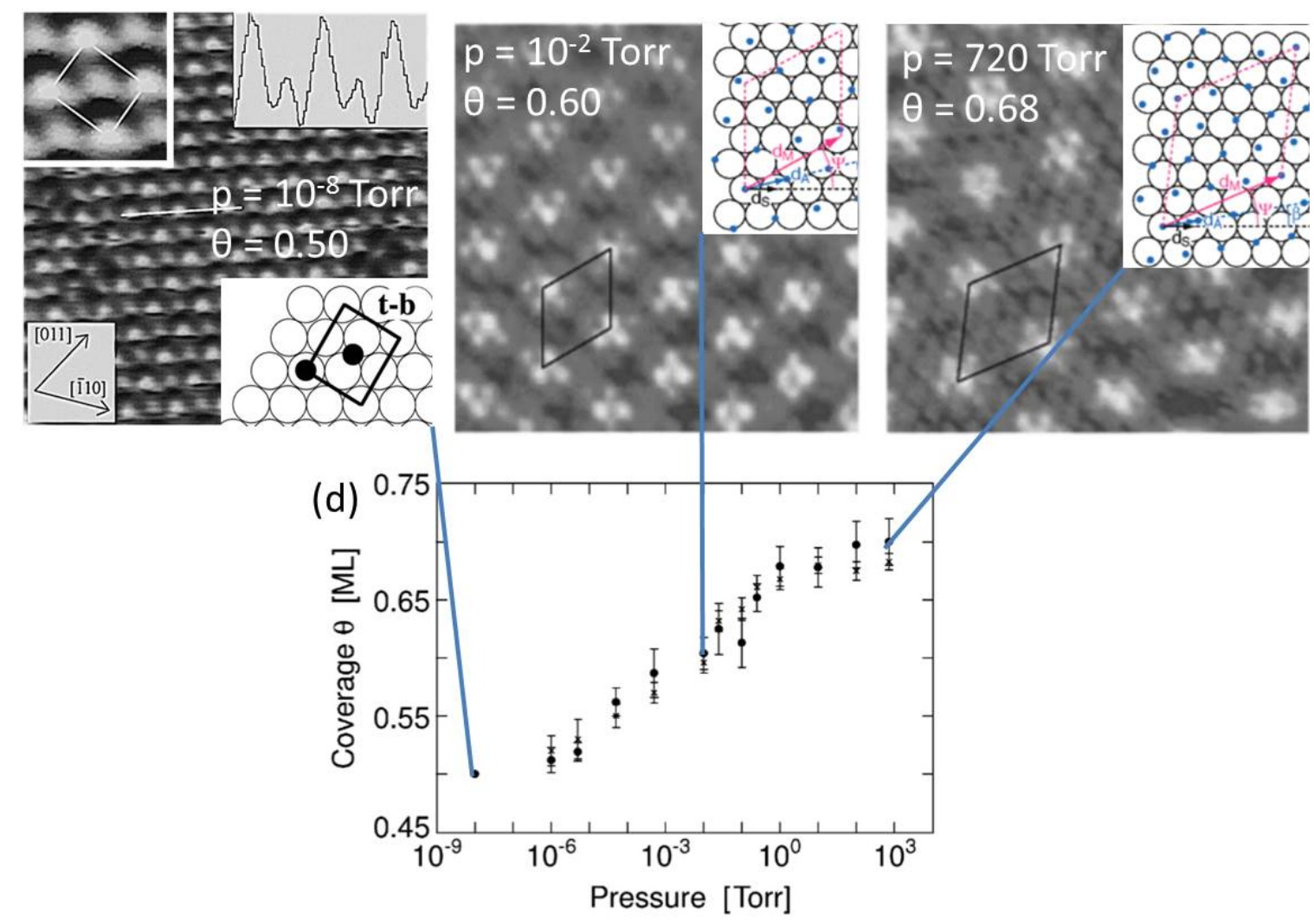

Figure 2-1. Equilibrium adlayer structures of CO formed on Pt(111). The STM images (a), (b) and (c) are shown for variable $\mathrm{CO}$ background pressure, $\mathrm{p}_{\mathrm{co}}$. The values of $\mathrm{p}$ and the coverages, $\theta$, of each $\mathrm{CO}$ adlayer are indicated on the figure. The scan window in (a) is $7 \times 7 \mathrm{~nm}^{2}$; in (b) and (c) it is $5.5 \times 5.5 \mathrm{~nm}^{2}$. The proposed unit cells of the adlayers, determined by analysis of the Moiré fringes, are shown in the insets. (d) Variation of CO adlayer coverage as a function of p. Each data point is linked to the corresponding STM image. (a) reproduced with permission from [55], (b), (c) and (d) reproduced with permission from ref. [53].

(a)

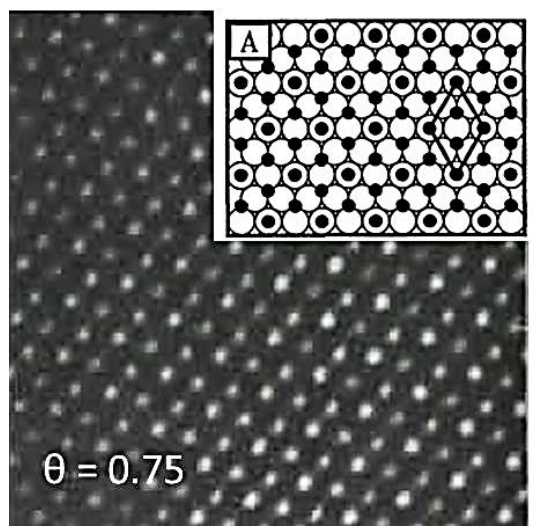

(b)

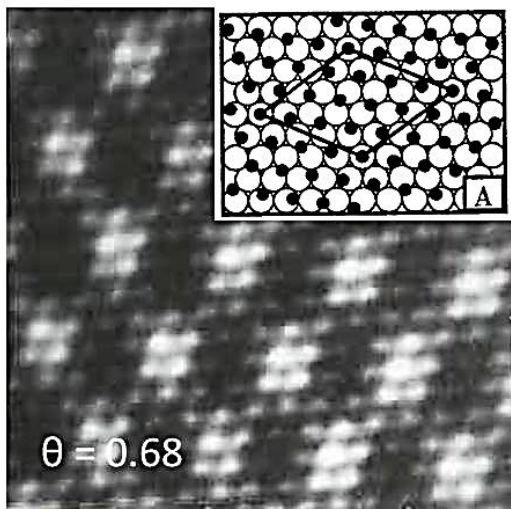

Figure 2-2. In-situ STM images $\left(5 \times 5 \mathrm{~nm}^{2}\right)$ obtained in $\mathrm{CO}$ saturated $0.1 \mathrm{M} \mathrm{HClO}_{4}$ at an applied potential of (a) 0 $\mathrm{V}$ vs. RHE and (b) $0.35 \mathrm{~V}$ vs. RHE. The structural models in the insets were deduced by comparison of the zcorrugation patterns with IRAS data. Reproduced with permission from ref. [54]. 
Although historically the $\mathrm{CO} / \mathrm{Pt}(111)$ system was first studied at the solid/gas interface, the first direct observation of higher-coverage phases occurred at the solid/liquid interface. As early as 1994 - 10 years before the high-pressure-STM data reported above - Villegas and Weaver published in-situ STM on Pt(111) in CO saturated electrolyte (see Figure 2-2) [54]. They found a change in the adlayer density with potential, specifically, a similar $(\sqrt{19} \times \sqrt{19}) \mathrm{R} 23.4^{\circ}-13 \mathrm{CO}(\theta=0.68 \mathrm{ML})$ structure as discussed above for $0.35 \mathrm{~V}$ vs. RHE, and an even more densely packed $(2 \times 2)-3 \mathrm{CO}$ structure $(\theta=0.75 \mathrm{ML})$ at $0 \mathrm{~V}$.

The high-coverage adlayers were not observed at the solid/gas interface as long as the adsorption took place at cryogenic temperatures and low CO pressures. The discovery of highercoverage phases at the solid-liquid interface further fuelled the idea of the two interfaces substantially differing in their CO adsorption properties. Before the in-situ STM observations in Figure 2-2, many $\mathrm{CO}$ adlayers formed at the solid/liquid interface were studied with thermal desorption or electron diffraction after a transfer into UHV $[8,77,78]$. Those studies showed higher CO coverages than $\theta=0.5 \mathrm{ML}$, but did not exceed $\theta=0.67 \mathrm{ML}$, i.e., the $\sqrt{\mathbf{1 9}} \times \sqrt{\mathbf{1 9}}$ pattern could not be observed ex-situ. As discussed in detail in ref. [79], it is now accepted that most adlayers formed at the solid/liquid interface cannot be transferred for ex-situ analysis into UHV without changes in coverage or at least structure. By now, however, the availability of an increasing number of in-situ methods, including in-situ-STM (see above) [54,80], X-ray scattering [81][82], surface sensitive vibrational spectroscopy such as infrared absorption [56][83] or Sum Frequency Generation (SFG) $[48,51,57,59]$, and differential electrochemical mass spectroscopy (DEMS) [58] have substantially improved the picture of $\mathrm{CO}$ adsorption and oxidation at the solid/liquid interface. Similar successes were achieved for other systems. Hence, the application of UHV based methods for the ex-situ characterization of "electrochemical" adlayers was an important step towards a better microscopic understanding of electrocatalysis. Most results from those "emersion experiments", apart from a few strongly adsorbing halides, could not be confirmed by in-situ methods once such became available [79]. However, the insights obtained in UHV experiments turned out to be of substantial relevance, in particular if those experiments were performed at room temperature and under conditions of increased gas pressure. In contrast, traditional UHV experiments at cryogenic temperatures and gas dosing in the $10^{-6} \mathrm{mbar}$ range may generally not be sufficient to "model" electrochemically relevant interfaces. The main reason is the lack of thermal fluctuations in the adlayer which is decisive for the possibility of reaching high adsorbate coverages, which in turn are essential for many adlayers to actually become reactive (Brønstedt-Polanyi-Evans relation $[75,76]$ ). 


\section{Bimetallic model surfaces prepared in UHV}

\subsection{Coupling electrochemistry to UHV}

UHV methods were historically introduced to electrochemical research to provide ex-situ analysis of the solid/liquid interface after emersion and transfer into vacuum. Such experiments are still common, but the focus shifted from attempting to understand the (rather weakly bound) adlayers towards analysing the electronic structure of the electrode itself, e.g., using X-Ray induced Photoemission $[7,8,33,36,84-91]$.

For the preparation of well-defined model electrodes, on the other hand, UHV continuously gained importance of the last two decades $[8,29,33,36,84-86,90-96]$. Planar model systems offer a high degree of control over their composition and structure. In particular, the distribution of the components parallel and perpendicular to the surface can be measured and controlled with high precision. Studies at electrodes with systematically varied surface structures and compositions reveal valuable insights into electrocatalytic reaction mechanisms and show pathways towards an improvement of electrode materials via a rational design. For some time, there was a gap between the versatility of well-defined bimetallic surfaces that could be prepared for (electrochemically motivated) surface science studies and those systems that were actually used for electrochemical experiments. Increasing interest in electrocatalysis research also fuelled the development of improved experimental transfer setups that facilitate the combination of UHV preparation and analysis on the one hand and state-of-the-art electrochemistry on the other $[8,97,98]$. A recently published example is shown in Figure 3-1.

A key feature of the EC chamber depicted in Figure 3-1 is the O-ring sealed flow cell (see also [99]), which offers two main advantages. First, only the cleaned and well-defined surface of the planar model electrode (here: $\mathrm{Pt}(111)$ ) is in touch with the electrolyte. This avoids problems with the sample perimeter being wetted, which is often contaminated by other metals during sputter cleaning [8]. Second, the option of working either in still or in flowing electrolyte, combined with a small electrolyte volume, comes with the potential opportunity of downstream analysis of the electrolyte, e.g., by mass spectroscopy [100]. 

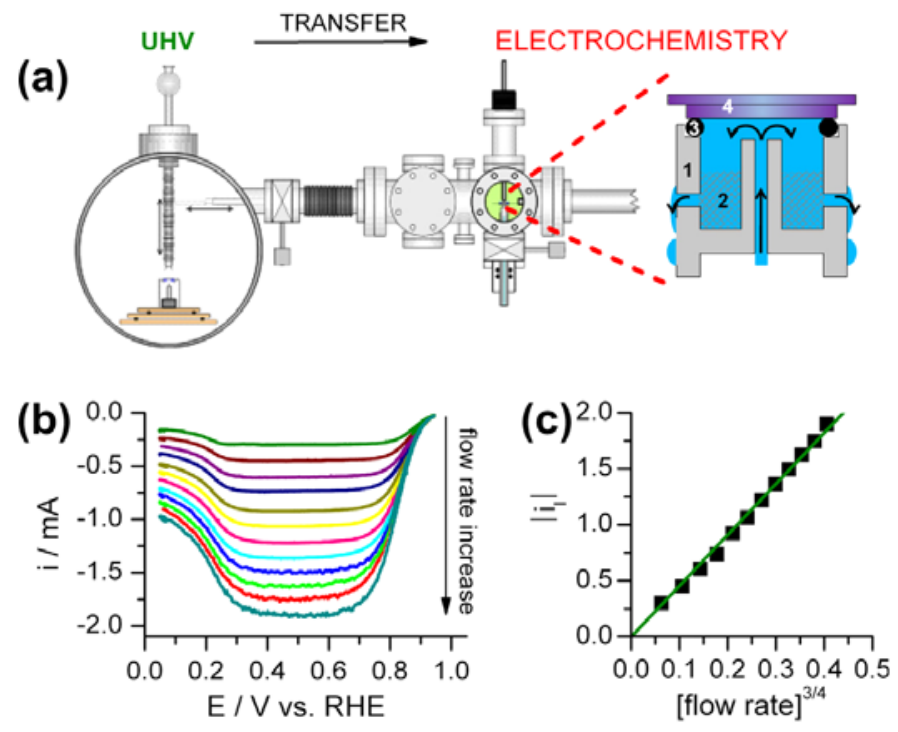

Figure 3-1. (a) Schematic representation of an UHV-electrochemistry transfer system (from ref. [98]) and cross section of a "nozzle cell" for kinetic ORR measurements, (b) ORR polarization curves in $\mathrm{O}_{2}$ saturated $0.1 \mathrm{M}$ $\mathrm{HClO}_{4}$ at $50 \mathrm{mV} \mathrm{s}^{-1}$ on Pt(111); electrolyte flow rates from $3 \mathrm{~mL} \mathrm{~min}^{-1}$ to $18 \mathrm{~mL} \mathrm{~min}^{-1}$ in steps of $1.5 \mathrm{~mL} \mathrm{~min}^{-1}$; (c) plot of the limiting currents for the ORR vs. the flow rate to the power of $3 / 4$.

\subsection{Electrochemistry at UHV prepared bulk alloy surfaces: Pt $_{3} S n$}

As mentioned in the introduction, early UHV/EC transfer setups were designed for experiments at monometallic, UHV-prepared single crystal surfaces. Even after the preparation by flame annealing had become state-of-the art [101], preparation in UHV through a combination of sputter cleaning and annealing remained the method of choice for alloy surfaces (Figure 1-1e). Apart from the clean conditions, UHV offers standardized methods to analyse the structure and composition of surfaces during and after the preparation procedures. Generally, metals intermixed with the intention to tune the (electro-)catalytic properties will differ in their surface free energies. Hence, thermal annealing in vacuum $[32,102,103]$ or gas $[104,105]$ will lead to the enrichment of one or the other component (Figure 1-1f) - with obvious consequences for the (electro-)chemical surface properties.

Figure 3-2 shows results from such a study, which in this case aimed at the structure sensitivity of $\mathrm{CO}$ electrooxidation at $\mathrm{Pt}_{3} \mathrm{Sn}$ single crystal surfaces $[8,106,107]$. The samples compared in the cited work were cleaned by ion bombardment (sputtering) in UHV. Two of them (see Figure 3-2) were subsequently annealed to obtain smooth surfaces. The cyclic voltammograms indicate the electrocatalytic superiority of the (111) over the (110) surface, as apparent from the high CO oxidation currents observed at low potentials. However, a thorough analysis of the influence of the 
preparation procedure on the structure and composition was only performed in a subsequent study, after the electrocatalytic experiments had been performed $[108,109]$.

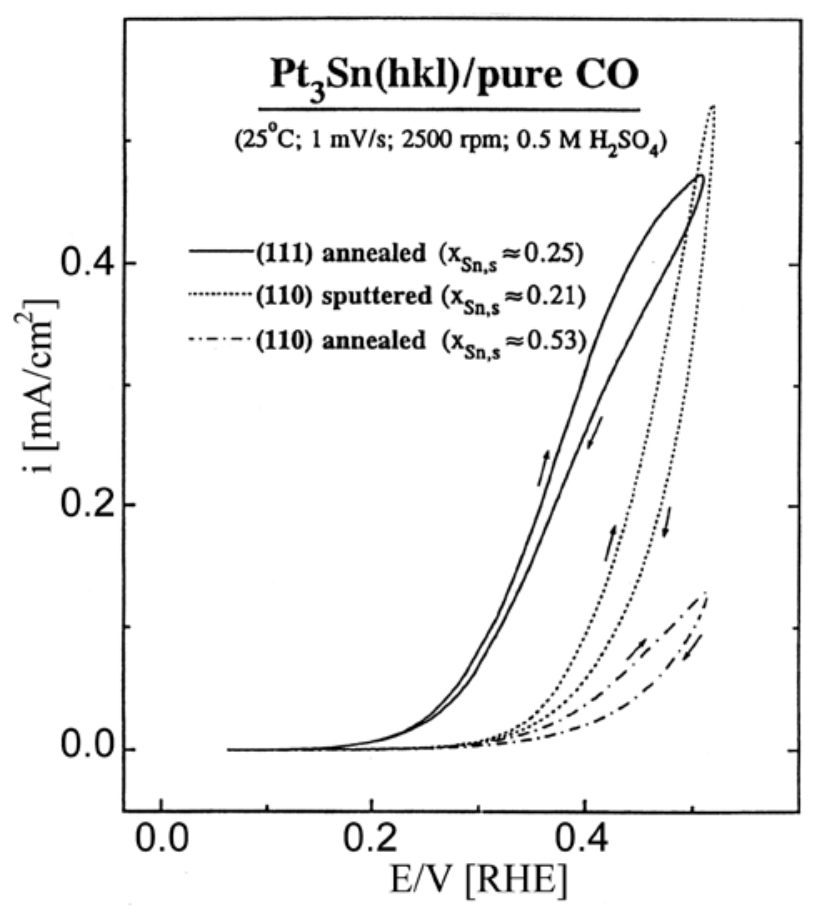

Figure 3-2. Current-potential curves $\left(1 \mathrm{mV} \mathrm{s}^{-1}\right)$ for $\mathrm{CO}$ electrooxidation in $0.5 \mathrm{M} \mathrm{H}_{2} \mathrm{SO}_{4}$ at $25^{\circ} \mathrm{C}$ on three different UHV-prepared $\mathrm{Pt}_{3} \mathrm{Sn}(\mathrm{hkl})$ model electrodes mounted into a rotating disc configuration (2500 rpm). Prior to the positive going sweep, the electrode potential was held at $\sim 0.05 \mathrm{~V}$ for 3 minutes to ensure the complete CO poisoning of the surfaces. Figure reproduced with permission from [110].

(a)

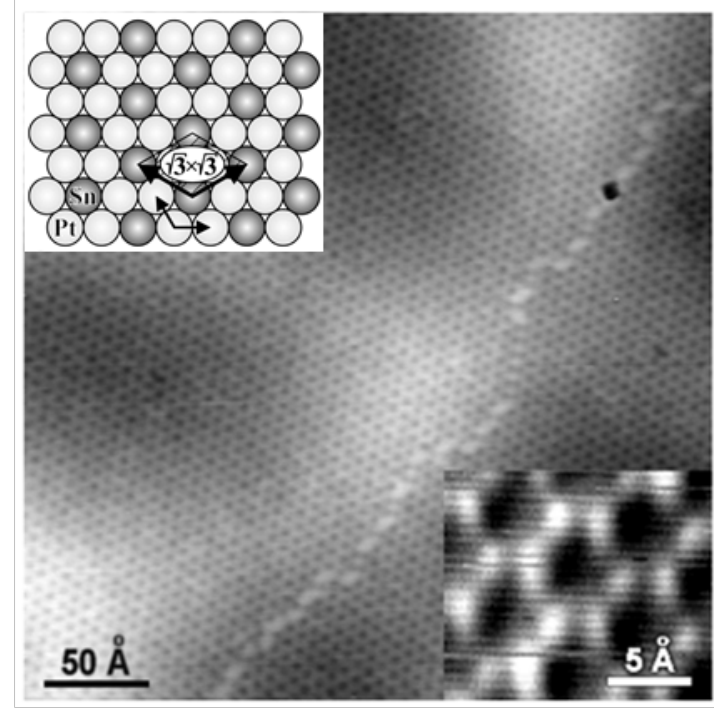

(b)

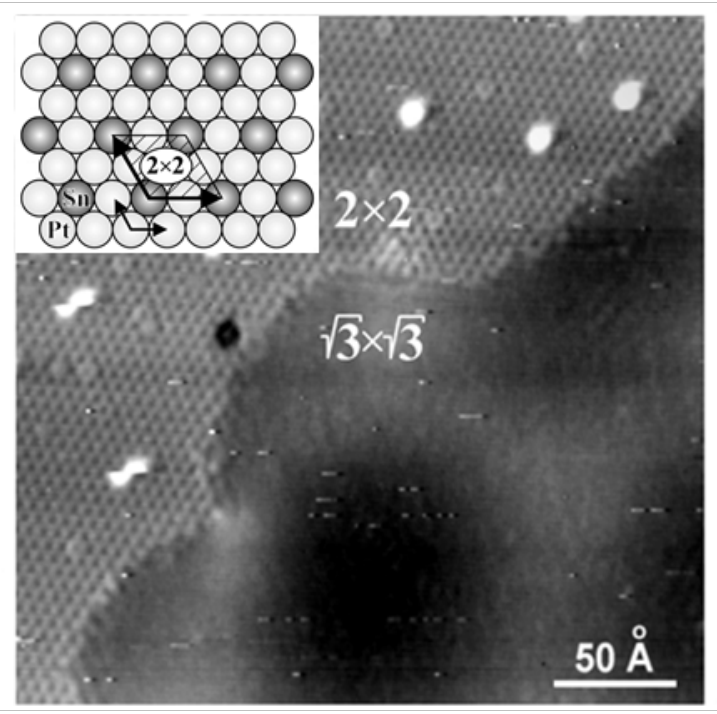

Figure 3-3. STM of $\mathrm{Pt}_{3} \mathrm{Sn}(111)$ surface phases; (a) $(\sqrt{3} \times \sqrt{3})-\mathrm{R}^{\circ} 0^{\circ}$ phase after annealing at $600 \mathrm{~K}$; inset: atomic resolution zoom ( $\mathrm{Pt}=$ dark, $\mathrm{Sn}=$ white, due to chemical contrast [111]); (b) coexistence of $\mathrm{p}(2 \times 2)$ and $(\sqrt{3} \times \sqrt{3})$ - 
R30 ${ }^{\circ}$ phases after annealing at $1000 \mathrm{~K}$. STM images reproduced from Kuntze et al. [112] by permission of the American Physical Society.

Low Energy Electron Diffraction (LEED) [108] revealed that with increasing temperature, the $\mathrm{Pt}_{3} \mathrm{Sn}(111)$ surface became increasingly dominated by a $\mathrm{p}(2 \times 2)$ pattern, with Sn surface content $=1 / 4$. At lower annealing temperatures, a $(\sqrt{3} \times \sqrt{3})$-R30 pattern, with $\mathrm{Sn}$ content $=1 / 3$, is dominant [108]. This was confirmed in a subsequent STM study [112], where chemical contrast [111] lets Pt atoms appear "higher" than Sn ones (see Figure 3-3). However, even at an annealing temperature of 1000 $K$, the authors still observed a coexistence of the two ordered phases. Hence, the annealing step to $950 \mathrm{~K}$ used in the electrochemical study [110] of Figure 3-2 must have led to a coexistence of the ( $\sqrt{3}$ $x \sqrt{3})-R 30^{\circ}$ and the $p(2 \times 2)$ structures. Hence, the current observed at every given potential must reflect a weighted sum of the currents generated in the $(\sqrt{3} \times \sqrt{3})-R 30^{\circ}$ and the $p(2 \times 2)$ dominated regions.

The following sections will show a number of cases where quantitative analysis of smooth model electrodes by STM in UHV allowed a break-down of the overall electrochemical behaviour into a sum of well-understood parts. Similar to Figure 3-3b, areas with different chemical properties can laterally expand with dimensions of many $\mathrm{nm}$ up to $\mu \mathrm{m}$. An accurate quantitative analysis of such spatial patterns is very difficult with diffraction methods, but quite straightforward using STM. 


\subsection{Tuned adsorption properties: Pt mono- and multilayers on $\operatorname{Ru}(0001)$}

\subsubsection{Strain and vertical ligand effects in experiment and theory}

This section will show an example of a smooth overlayer model system (cf. Figure 1-1g) that consists of areas with different local adsorption properties. Those adsorption properties can be directly observed by STM. We will then show that a combination of (i) an accurate statistical analysis of the surface morphology by STM and (ii) a calculation of the adsorption energies by density functional theory (DFT) is sufficient to accurately and quantitatively predict some key voltammetric features of the same samples. Metal vapour deposition in UHV in combination with surface sensitive spectroscopy and high-resolution STM is the most reliable way of preparing model surfaces that chemically and structurally match the "slab" type systems typically used in DFT calculations and thus allow a specific validation of predictions.

Due to its high activity in low temperature fuel cell anodes for the oxidation of CO contaminated $\mathrm{H}_{2}$ or the direct electrochemical oxidation of methanol, the metal combination Pt+Ru has attracted tremendous research activity over the last decades. Apart from the electrochemistry community [113-117], also the Surface Science community was significantly involved $[8,19,22,34,118-125]$. Early concepts to explain the enhanced electrocatalytic activity of Pt-Ru mainly refer to a bifunctional Langmuir-Hinshelwood mechanism, in which an oxygenated species formed at $\mathrm{Ru}$ by $\mathrm{H}_{2} \mathrm{O}$ dissociation acts as a co-reactant to remove CO from Pt sites [114]. As a result of the continuously improved microscopic picture of surface chemistry, however, more recent works put a particular emphasis on the influence of Pt-Ru bonds (ligand effect) and lattice strain on the local reactivity of Pt and $\mathrm{Ru}[19,22,99,122-125]$. These will affect the coverages of desired (e.g., H) and undesired (e.g., $\mathrm{CO})$ adsorbates and also the rates of the associated surface reactions [126].

Among the model surfaces studied in the cited works, atomically thin Pt films on $\mathrm{Ru}(0001)$ play a distinctive role. Pt was found to grow in atomically smooth, pseudomorphic layers on $\mathrm{Ru}(0001)$ : Pt atoms adopt the lateral atom-atom distance of the underlying $\mathrm{Ru}(0001)$ plane, which is $0.271 \mathrm{~nm}$ as compared to $0.277 \mathrm{~nm}$ in the Pt(111) surface. Compared to Pt(111), the Pt films are thus laterally compressed, which according to the d-band model of Hammer and Nørskov $[18,127]$ makes CO adsorption weaker. In addition to the lattice compression, the bonds to the underlying Ru atoms further destabilize the interaction of the Pt atoms with surface adsorbates, including $\mathrm{CO}$ $[18,19,22,125,127,128]$. The latter effect can be rationalized by a simple bond order argument: Pt is more strongly bound to Ru than to Pt [119], which reduces its bonding power for the interaction 
with a third species, e.g., an adsorbate. DFT calculations explicitly show for the cases of $\mathrm{CO}_{\mathrm{ad}},[19]$ $\mathrm{H}_{\mathrm{ad}},[22], \mathrm{O}_{\mathrm{ad}}[128]$ that the destabilizing effect of the Pt-Ru bond becomes weaker with increasing Pt layer thickness. For these surfaces, it is possible to work at corresponding systems in experiment and theory. Following the approach used for the images in Figure 2-1 [53], the following examples will demonstrate the use of STM to probe the CO adlayer patterns formed at room temperature and increased CO pressure on chemically different areas at the surface (see also refs.[129] and [103] for imaging of spatially varying adsorption properties).

\subsubsection{Direct observation of local adsorption properties through video-STM}

Figure 3-4a shows the surface morphology after deposition of 1.2 ML (monolayer, $1 \mathrm{ML}=$ one adsorbate or foreign metal atom per surface atom) Pt onto $\mathrm{Ru}(0001)$ at room temperature, followed by flash annealing to $800 \mathrm{~K}$. The morphology of the atomically smooth surface is characterized by ribbons of step decorations and hexagonal islands, where the local Pt film thickness is $2 \mathrm{ML}$. The remaining fraction of the surface is covered by a single Pt monolayer. Close to the buried $\mathrm{Ru}(0001)$ step edges, it is possible to record STM images at the boundaries between regions of $1 \mathrm{ML}$ and $2 \mathrm{ML}$ local Pt coverage where the topmost Pt atoms reside at almost the same height level. This allows for fast imaging of these regions in constant-height mode. A sequence of 163 STM images was recorded with a frame rate of five images per second, i.e., the overall sequence covers a period of $33 \mathrm{~s}$. The sample temperature was kept constant at $300 \mathrm{~K}$. Figure $3-4 \mathrm{~b}$ shows an atomic resolution STM image from this sequence (recorded in the area indicated by the small rotated square in Figure 3-4a) at conditions of ultrahigh vacuum $\left(10^{-10} \mathrm{mbar}\right)$. The $1 \mathrm{ML} \mid 2 \mathrm{ML}$ border is characterized by a line of fourfold hollow sites. This is due to the different stacking of the outermost layer with respect to the two underlying ones.

Figure 3-4c summarizes the experimental and calculated findings from ref. [19]. These are the DFT calculated Pt-CO binding energies and peak positions in temperature programmed desorption experiments of $\mathrm{CO}$ on Pt mono- and multilayers on Ru(0001) and on Pt(111). Experiments and calculations agree on the prediction that $\mathrm{CO}$ adsorption is weakest on $\mathrm{Pt}_{1 \mathrm{ML}} / \mathrm{Ru}(0001)$ and becomes stronger with the number of Pt layers. Even for Pt films with a thickness of 10 atomic layers, however, CO desorption is shifted to lower temperatures as compared to $\mathrm{Pt}(111)$. This can be explained by the pseudomorphic growth of $\mathrm{Pt}$ on $\mathrm{Ru}(0001)$ that was shown to persist up to $\mathrm{Pt}_{10 \mathrm{ML}} / \mathrm{Ru}(0001)$ [123]. The DFT calculations confirm that the compression alone is sufficient to explain the persisting gap in CO stability on $\mathrm{Pt}_{10 \mathrm{ML}} / \mathrm{Ru}(0001)$ vs. $\mathrm{Pt}(111)$ (data point on the right hand side of Figure 3-4c) [19]. It should be noted that the CO desorption peak for bare $\mathrm{Ru}(0001)$ is at around $480 \mathrm{~K}$ [130] i.e., the adsorption on that surface is stronger than on Pt(111) or on Ru supported Pt thin films. 

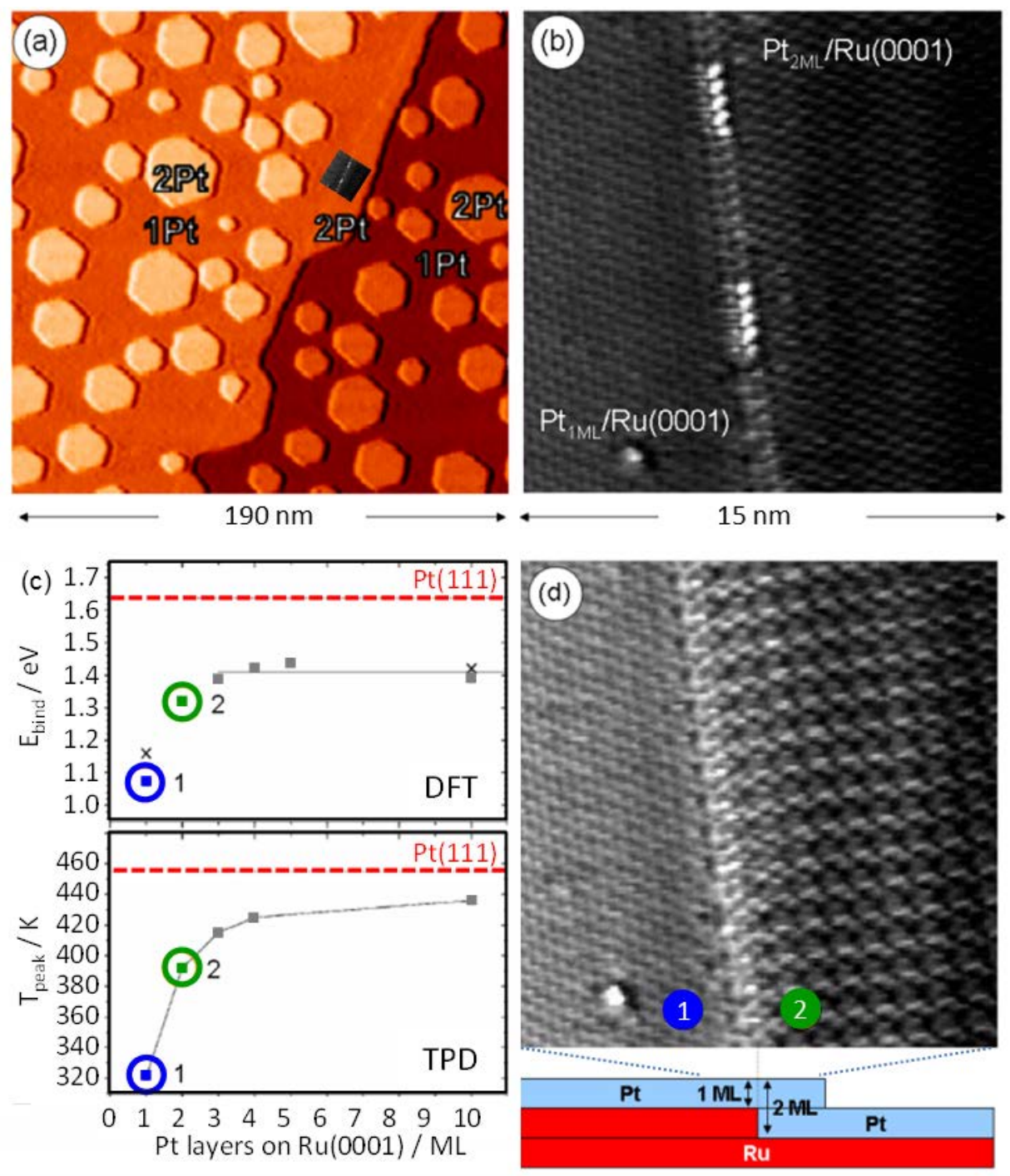

Figure 3-4. Local adsorption properties directly observed by fast STM. (a) STM image of 1.2 ML Pt/Ru(0001) after annealing at $800 \mathrm{~K}$. Regions with $1 \mathrm{ML}$ and $2 \mathrm{ML}$ Pt coexist. (b) Atomically resolved image (recorded with 5 images $\mathrm{s}^{-1}$ in constant height mode) of the boundary between regions with locally $1 \mathrm{ML}$ and $2 \mathrm{ML} \mathrm{Pt}$. A smaller version of the image is overlaid on the morphology in (a) to indicate where it was recorded. (c) CO adsorption properties of pseudomorphic Pt films with increasing thickness according to ref. [19]. Top plot: adsorption energies; bottom plot: temperature programmed desorption peak temperatures; the dashed lines show the respective values for $\mathrm{Pt}(111)$ as a reference. (d) Atomically resolved image of the same region as in (b), but at a CO pressure of $10^{-5}$ mbar. The frame size in this image is the same as in (b). The circles marked by 1 and 2 link the surface regions in (d) to the corresponding data points in (c). The diagram at the bottom right indicates how the morphology around the step edge allows imaging $1 \mathrm{ML}$ and $2 \mathrm{ML}$ of Pt at almost the same geometric level of height. Reproduced with permission from ref. [131]. 
According to Figure 3-4c, the peaks of thermal CO desorption from $1 \mathrm{ML}$ and $2 \mathrm{ML}$ Pt on $\mathrm{Ru}(0001)$ are at $320 \mathrm{~K}$ and $390 \mathrm{~K}[19]$, respectively. At $300 \mathrm{~K}$, this intuitively suggests that CO should be quite unstable on $\mathrm{Pt}_{1 \mathrm{ML}} / \mathrm{Ru}(0001)$, whereas at the same temperature the corresponding $\mathrm{CO}$ adlayer adsorbed on $\mathrm{Pt}_{2 \mathrm{ML}} / \mathrm{Ru}(0001)$ should be similar to the one on $\mathrm{Pt}(111)$. This is confirmed by the following observation: when the UHV chamber is backfilled to a CO pressure of $10^{-5} \mathrm{mbar}$ with the sample kept at $300 \mathrm{~K}$ (Figure 3-4d), the $\mathrm{Pt}_{1 \mathrm{ML}} / \mathrm{Ru}(0001)$ region appears largely unaffected, i.e., CO could only be present as a mobile adlayer that remains invisible to STM. This is different from the $\mathrm{Pt}_{2 \mathrm{ML}} / \mathrm{Ru}(0001)$ region on the right hand side of Figure $3-4 \mathrm{~d}$, in which a superstructure with a quadratic unit cell becomes visible. This structure is the well-known $c(4 \times 2)$ phase that is formed on $\mathrm{Pt}(111)$ at a CO coverage of $0.5 \mathrm{ML}$ (see Figure 2-1a) [71,132]. The $\mathrm{c}(4 \times 2) \mathrm{CO}$ adlayer gives rise to a desorption peak at $\mathrm{T}>450 \mathrm{~K}$ on $\mathrm{Pt}(111)$. For $\mathrm{Pt}_{2 \mathrm{ML}} / \mathrm{Ru}(0001)$, however, the desorption peak was already observed at $390 \mathrm{~K}$, with measurable desorption rates even at $300 \mathrm{~K}$ [19]. This fits to the observation that the $c(4 \times 2)$ pattern in Figure $3-4 d$ disappeared a few minutes after the chamber was pumped down again to UHV conditions.

\subsubsection{Closing the loop: reality check for DFT predicted isotherms}

The STM observation of $\mathrm{CO}$ on $\mathrm{Pt}_{1 \mathrm{ML}} / \mathrm{Ru}(0001)$ and $\mathrm{Pt}_{2 \mathrm{ML}} / \mathrm{Ru}(0001)$ correspond to one point in the adsorption isotherm of either model surface. In the experiment, both areas are in independent equilibrium with the gas phase, i.e., the coexisting regions with different local adsorption properties do not "see" each other when it comes to the local CO coverage (the boundary may again have its own adsorption sites). In the following, we will demonstrate that the observed behaviour is in quantitative agreement with the DFT calculated adsorption energies in Figure 3-4c [19]. For that purpose, we calculate the adsorption isotherms for both surfaces, starting with a published curve for $\mathrm{CO}$ on $\mathrm{Pt}(111)$ and then modifying this curve by varying only the adsorption energy of $\mathrm{CO}$ on $\mathrm{Pt}$ according to Figure 3-4c [19]. We use the isotherm obtained by Poelsema et al. by He scattering at $\mathrm{Pt}(111)$ at varied CO pressure [72]. The same study served as a key reference point in a comprehensive computational treatment of $\mathrm{CO}$ phases on $\mathrm{Pt}(111)$ [71]. Poelsema et al. found that $\mathrm{CO}$ adsorption on $\mathrm{Pt}(111)$ at coverages $\theta_{\mathrm{co}}<0.1 \mathrm{ML}$ can be fitted by a Frumkin- (= FowlerGuggenheim) isotherm of the form

$p_{C O}=\frac{\theta_{C O}}{1-\theta_{C O}} \kappa T^{3} \exp \left(-\frac{E_{d, P t(111), \theta_{C O}=0}+\varepsilon \theta_{C O}}{k_{B} T}\right)$ $\theta_{C O}=$ CO coverage, $p_{C O}=$ CO pressure, $T=$ surf. temp., $k_{B}=$ Boltzmann constant, $\kappa=12.5$ mbar $K^{-3}=$ const., $E_{d, P t(111), \theta_{C O}=0}=1.378 \mathrm{eV}=$ desorption barrier of $\mathrm{CO}$ on Pt(111) at $\theta_{C O}=0, \varepsilon=0.71 \mathrm{eV}=$ mean field repulsive interactions 
In the cited work, a good data fit at $T=402 \mathrm{~K}, 415 \mathrm{~K}, 427 \mathrm{~K}, 440 \mathrm{~K}$, and $452 \mathrm{~K}$ was obtained with the coverage and temperature independent value of $\kappa$ as shown above. The constant $\varepsilon$ was found to be independent of $\theta_{C O}$ and $T$. Figure 3-5 shows the isotherm for $402 \mathrm{~K}$. For $\theta_{C O}<0.17 \mathrm{ML}$ the curve is drawn as solid line. For higher coverages, the cited work did not explicitly confirm the isotherm experimentally, which is why this part is considered an extrapolation and therefore drawn as dotted line. For $\mathrm{CO}$ on $\mathrm{Pt}(111)$, reversible adsorption at $300 \mathrm{~K}$ has only been studied for $\theta_{C O}>0.5 \mathrm{ML}$ [53]; see the discussion of Figure 2-1. Only the high-coverage structures formed in this regime imply sufficiently large desorption rates to establish adsorption equilibrium in a reasonable time at that temperature. The small circles reflect the STM-based data points from ref. [53], which were also plotted in Figure 2-1d (note that in Figure 3-5 we omitted the error bars for the sake of clarity of the plot).

Based on the Frumkin isotherm and the parameters listed above, one can calculate a hypothetical isotherm for $\mathrm{CO}$ on $\mathrm{Pt}(111)$ at $300 \mathrm{~K}$, plotted as a dashed line in Figure 3-5. CO pressures of $p_{\mathrm{CO}}<10^{-9} \mathrm{mbar}$ would have to be established and controlled to attain equilibrium coverages of $\theta_{C O}<0.5 \mathrm{ML}$. Reliable measurements of $\mathrm{CO}$ equilibrium coverages in this pressure regime would be very difficult due to the influence of the rest gas and the slow adsorption/desorption rates. Nevertheless, the hypothetical isotherm points to the data point at the low-coverage limit of the STM study at $300 \mathrm{~K}$ [53], which nicely closes the validation loop.

The DFT calculated CO binding energies on Pt(111), $\mathrm{Pt}_{1 \mathrm{ML}} / \mathrm{Ru}(0001)$, and $\mathrm{Pt}_{2 \mathrm{ML}} / \mathrm{Ru}(0001)$ (see Figure 3-4c) directly yield isotherms for $\mathrm{CO}$ on $\mathrm{Pt}_{1 \mathrm{ML}} / \mathrm{Ru}(0001)$ and $\mathrm{Pt}_{2 \mathrm{ML}} / \mathrm{Ru}(0001)$ (dash-dotted lines in Figure 3-5). The curves use $E_{d, P t_{1 M L} / R u(0001), \theta_{C O}=0}=0.928 \mathrm{eV}$ and $E_{d, P t_{2 M L} / R u(0001), \theta_{C O}=0}=$ $1.158 \mathrm{eV}$ instead of $E_{d, P t(111), \theta_{C O}=0}=1.378 \mathrm{eV}$. The two values for the energy barriers were directly calculated from the experimentally found value for $\mathrm{Pt}(111)[71,72]$ and the differences between the binding energies as obtained by DFT, i.e. $0.45 \mathrm{eV}$ and $0.22 \mathrm{eV}$ for $\mathrm{Pt}_{1 \mathrm{ML}} / \mathrm{Ru}(0001)$ and $\mathrm{Pt}_{2 \mathrm{ML}} / \mathrm{Ru}(0001)$, respectively (in Figure 3-4c those are the vertical distances of points 1 and 2 with respect to the dashed line). The absolute values of the DFT-based binding energies were not considered for calculating the curves. All other parameters in the isotherm were kept at the values found for $\mathrm{Pt}(111)$. This is similar to the treatment of $\mathrm{H}$ adsorption on the same surfaces discussed in the context of Figure 3-6 in this paper [22]. 


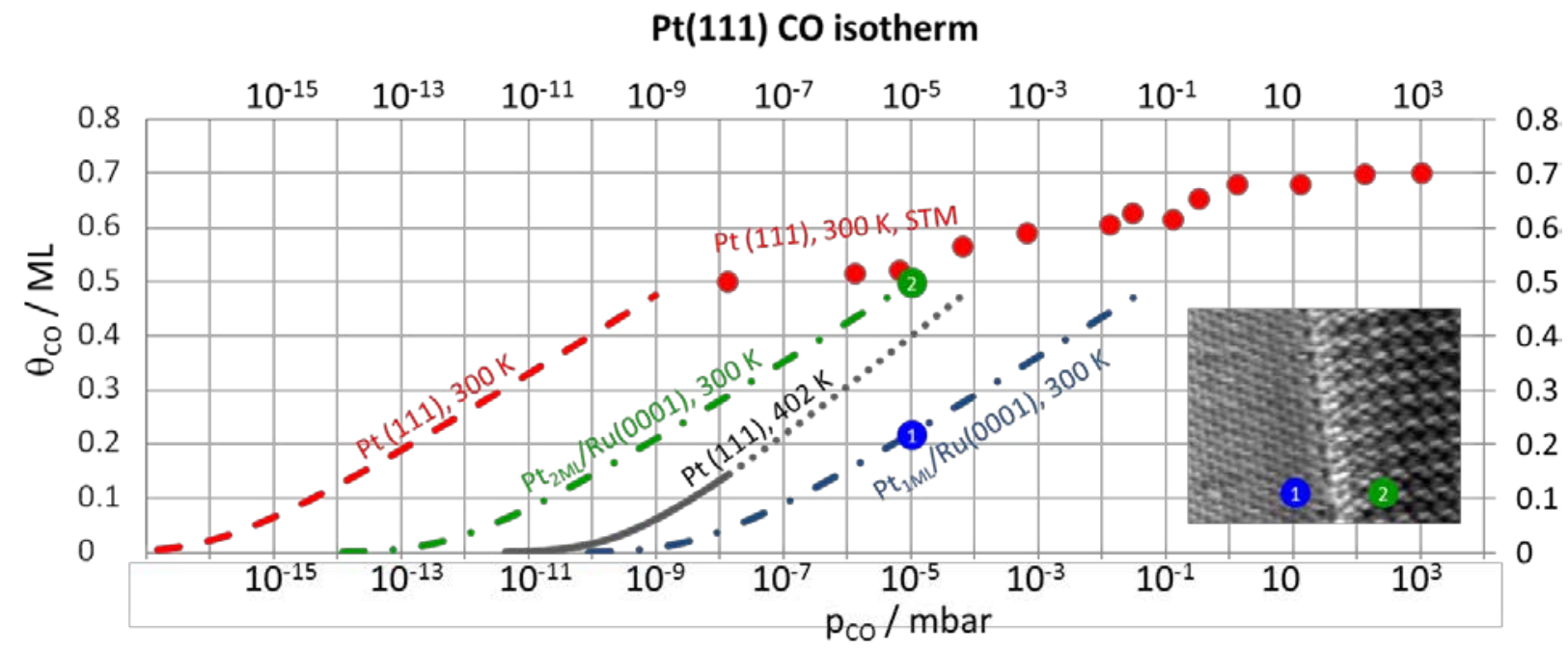

Figure 3-5. Adsorption isotherms of $\mathrm{CO}$ on $\mathrm{Pt}(111), \mathrm{Pt}_{1 \mathrm{ML}} / \mathrm{Ru}(0001)$ and $\mathrm{Pt}_{2 \mathrm{ML}} / \mathrm{Ru}(0001)$. For $\mathrm{Pt}(111)$, experimental data points were taken from ref. [133] (STM data, small circles) and ref. [72] (solid line). The dashed line is the hypothetical isotherm for $\mathrm{CO}$ on $\mathrm{Pt}(111)$ at $300 \mathrm{~K}$. The dash dotted lines are calculated isotherms based on the experiments in ref. [72] and the adsorption energies of $\mathrm{CO}$ on $\mathrm{Pt}_{1 \mathrm{ML}} / \mathrm{Ru}(0001)$ and $\mathrm{Pt}_{2 \mathrm{ML}} / \mathrm{Ru}(0001)$ from ref. [19]. The two spots marked (1) and (2) reflect the points observed by STM at $300 \mathrm{~K}$ and $\mathrm{p}_{\mathrm{CO}}=10^{-5} \mathrm{mbar}$ (see inset and Figure 3-4). Reproduced with permission from ref. [131].

The two isotherms predicted by this DFT based extrapolation agree well with the following experimental findings:

1. The CO coverage for $\mathrm{Pt}_{1 \mathrm{ML}} / \mathrm{Ru}(0001)$ at $p_{\mathrm{CO}}=10^{-5} \mathrm{mbar}$ would be $\theta_{C O} \sim 0.25 \mathrm{ML}$ (see the point marked "1" on Figure 3-5). A CO adlayer with $\theta_{C O}<0.33 \mathrm{ML}$ can be expected to be too mobile for STM imaging at $300 \mathrm{~K}$ on any of the Pt surfaces discussed here. This assumption is justified by the known low lateral corrugation of the CO adsorption energy on $\mathrm{Pt}(111)$ [71]. STM imaging of $\mathrm{CO}$ adlayers is only possible once $\mathrm{CO}$ is immobilized by CO-CO repulsion. The barrier for $\mathrm{CO}$ hopping between different adsorption sites should be even lower on $\mathrm{Pt}_{1 \mathrm{ML}} / \mathrm{Ru}(0001)$ or $\mathrm{Pt}_{2 \mathrm{ML}} / \mathrm{Ru}(0001)$, thus making STM observations of low CO coverages at 300 $\mathrm{K}$ even less likely. Hence, the fact that no evidence for $\mathrm{CO}$ is visible on the $\mathrm{Pt}_{1 \mathrm{ML}} / \mathrm{Ru}(0001)$ surface (see inset of Figure 3-5) is fully consistent with the isotherm.

2. According to Figure $3-5, p_{\mathrm{CO}}=10^{-5}$ mbar at $300 \mathrm{~K}$ should yield a CO coverage of $0.5 \mathrm{ML}$ on $\mathrm{Pt}_{2 \mathrm{ML}} / \mathrm{Ru}(0001)$, in perfect agreement with the STM observation (see point marked " 2 " and inset of Figure 3-5). Furthermore, the fact that the $c(4 \times 2)$ pattern disappears when the CO supply is stopped confirms that it indeed belongs to a reversibly adsorbed adlayer in equilibrium with the gas phase. 


\subsubsection{Closing the loop: DFT predicted cyclic voltammetry features}

The data discussed in the previous section demonstrates that pseudomorphic Pt layers on Ru(0001) indeed behave like electronically modified $\mathrm{Pt}(111)$ when it comes to the adsorption of $\mathrm{CO}$ as a probe molecule. For the solid/liquid interface, the same trend can be verified directly with adsorbed hydrogen as a probe species. Accurate quantitative adsorption data obtained through cyclic voltammetry were reported for the equilibrium $H^{+}+e^{-} \rightleftharpoons H_{a d}[49,134-143]$, where the potential is varied instead of the $\mathrm{H}_{2}$ partial pressure at different Pt single crystal surfaces. By analysis of the experimental data [134] and by comparison with Monte Carlo modelling $[144,145]$ it has been established that the region of underpotentially deposited hydrogen (upd- $\mathrm{H}_{\mathrm{ad}}$ ) is well described by a Frumkin isotherm incorporating repulsive interactions between the adsorbed hydrogen atoms. Based on coverage-dependent adsorption energies for $\mathrm{H}_{\mathrm{ad}}$ calculated by density functional theory (DFT), Karlberg et al. obtained good agreement with experiment in modelling the most important features of the regions associated with the formation of upd- $\mathrm{H}_{\mathrm{ad}}$ in the base voltammograms for $\mathrm{Pt}(111)$ and Pt(100) [145]. In particular, the DFT predictions about the differences between these two surfaces agree quite well with the corresponding experimental data. Quantitative deviations from experimental observations mainly concerned the absolute onset potentials for $\mathrm{H}_{\mathrm{ad}}$ formation, and the strength of the lateral interactions between the adsorbed hydrogen atoms, which were underestimated in the ab-initio based predictions for both surfaces (see Table 1 in ref. [135]).

As will be demonstrated in the following, DFT calculated adsorption energies allow modelling of the voltammetric upd- $\mathrm{H}_{\mathrm{ad}}$ formation with a much higher accuracy when experimental results for a reference surface are taken into account as anchoring point. As model surfaces, we have chosen the same pseudomorphic Pt films on $\mathrm{Ru}(0001)$ (in the following referred to as $\mathrm{Pt}_{\mathrm{x}-\mathrm{ML}} / \mathrm{Ru}(0001)$, where $\mathrm{x}$ is the $\mathrm{Pt}$ coverage in $\mathrm{ML}=$ monolayers and ranges from $\mathrm{x}=1.1 \ldots 3.5,1 \mathrm{ML}=1 \mathrm{Pt}$ atom per $\mathrm{Ru}$ surface atom) as studied in the previous section. Again, $\mathrm{Pt}(111)$ serves as a reference surface. The samples were prepared by vapour deposition in ultrahigh vacuum (UHV) followed by annealing to $850 \mathrm{~K}-950 \mathrm{~K}$ to attain a smooth morphology. The thicknesses of the Pt layers were coarsely determined by Auger-Electron spectroscopy (AES), but the chemically relevant details about the distribution of local thicknesses are based on scanning tunnelling microscopy (STM) data. As visible in the STM data in Figure 3-6a - e, the annealed Pt exhibits a Stranski-Krastanov growth mode, with a closed first layer and an onset of 3D growth for thicknesses $>2 \mathrm{ML}$. The area fractions of the respective local thicknesses are plotted in the histograms in Figure 3-6f-j.

The cyclic base voltammograms recorded for these surfaces are plotted in Figure $3-6 k-0$. The profile for Pt(111) plotted in Figure 3-6k shows the typical sigmoidal upd- $\mathrm{H}_{\mathrm{ad}}[49,101,137,138]$ and 
"butterfly-type" $\mathrm{OH}_{\mathrm{ad}}[101,146,147]$ regions at $\phi<0.4 \mathrm{~V}$ and $\phi>0.6 \mathrm{~V}$, respectively, which are separated by the "double-layer region" [143] dominated by capacitive currents. Apart from Figure 3-6I, which shows the $\mathrm{CV}$ for $\theta_{\mathrm{Pt}}=1.1$, all other voltammograms qualitatively resemble this shape. The main peculiarity about Figure 3-6I is the occurrence of higher pseudocapacitive currents in the region $0.4 \mathrm{~V}<\phi<0.6 \mathrm{~V}$, which are not observed in any of the other voltammograms. It is likely that these currents reflect adsorption/desorption at/from uncovered Ru areas and/or locally alloyed surface regions [148]. The potential regions related to $u p d-\mathrm{H}_{\mathrm{ad}}$ and $\mathrm{OH}_{\mathrm{ad}}$ formation at the $\mathrm{Pt}$ films are shifted to lower and higher potentials, respectively, compared to the CV for Pt(111). This means that both adsorbates bind more weakly to $\mathrm{Pt}_{\mathrm{x}-\mathrm{ML}} / \mathrm{Ru}(0001)$ (at least for $\mathrm{x}<4$ ) than to $\mathrm{Pt}(111)$. Moreover, the deviation from the Pt(111)-like behaviour becomes smaller with increasing Pt coverage. 


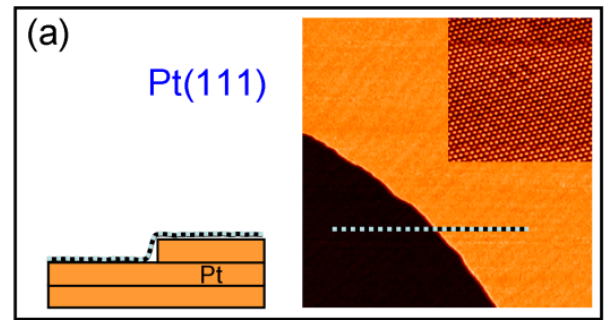

(b)
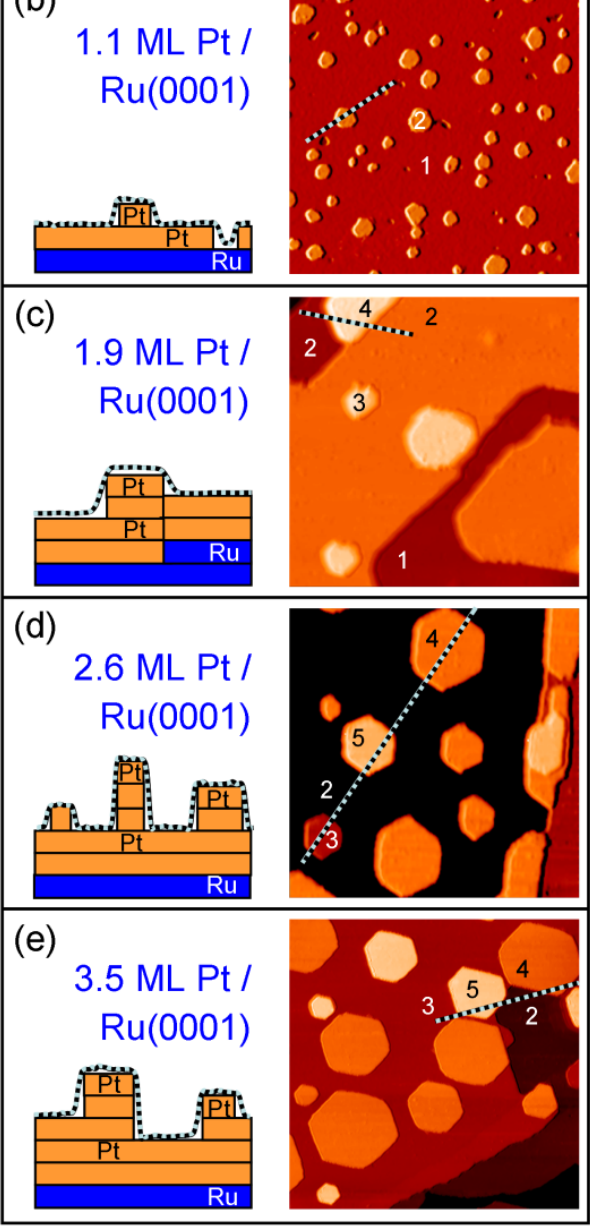
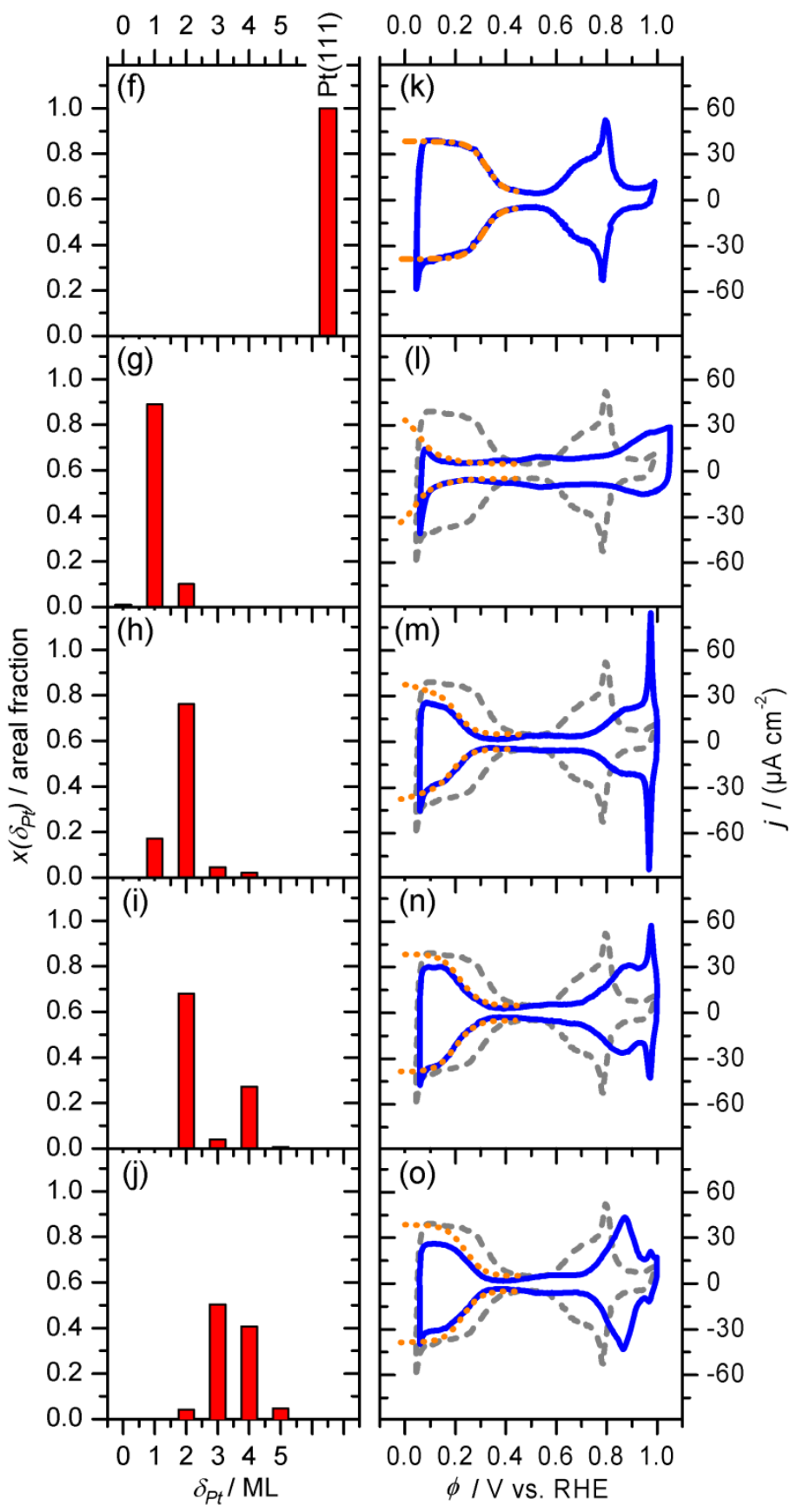

Figure 3-6. STM images (a-e, size $200 \times 200 \mathrm{~nm}^{2}$ ), film thickness histograms (f-j), and cyclic base voltammograms $(k-0)$ of $\mathrm{Pt}(111)(a, f, k)$ and four pseudomorphic $\mathrm{Pt}_{\mathrm{x}-\mathrm{ML}} / \mathrm{Ru}(0001)$ thin films. Line profiles extracted along the dotted lines are plotted and visualized together with the STM data. The numbers in STM images denote local Pt layer thickness $\theta_{\mathrm{pt}}$. The histograms show surface fractions covered by regions with $\theta_{\mathrm{Pt}}=0 \ldots 5$. The Voltammograms were recorded in $0.1 \mathrm{M} \mathrm{HClO}_{4}$ with $0.05 \mathrm{~V} \mathrm{~s}^{-1}$, and within the ranges $0.05 \mathrm{~V}-1 \mathrm{~V}(\mathrm{k})$ and 0.06 $-1 \mathrm{~V}(\mathrm{I}-\mathrm{o})$. The voltammogram for $\mathrm{Pt}(111)$ is re-plotted as dashed line in (I-o) for comparison. The dash-dotted line in $(\mathrm{k})=$ sigmoidal fit to $\mathrm{Pt}(111)$ voltammogram; the dotted lines in $(\mathrm{I}-\mathrm{o})$ = simulated voltammograms (see text). Reproduced with permission from ref. [22]. 


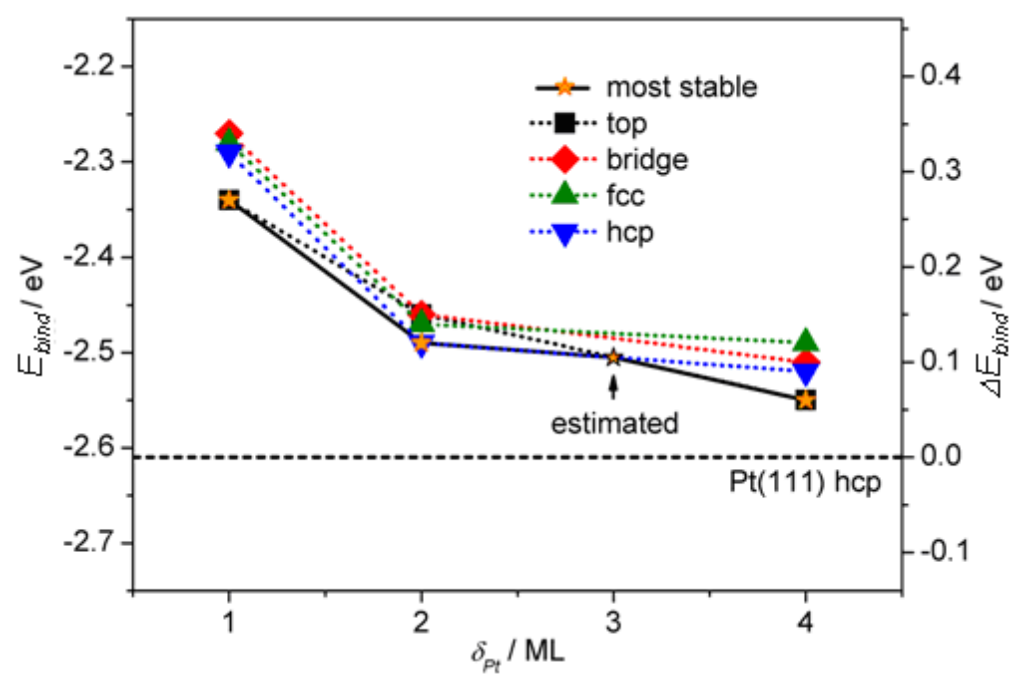

Figure 3-7. DFT calculated binding energies $E_{b i n d}$ for atomic hydrogen at pseudomorphic Pt films on $\mathrm{Ru}(0001)$ of variable thickness (see text). Stars $=$ most stable adsorption states. Value for $\mathrm{Pt}_{3 \mathrm{ML}} / \mathrm{Ru}(0001)$ estimated by interpolation. $\mathrm{E}_{\mathrm{bind}}$ for hcp sites on $\mathrm{Pt}(111)$ is shown as reference (dashed line) Axis on the right hand side: $\Delta \mathrm{E}_{\text {bind }}=\mathrm{E}_{\text {bind }}-\mathrm{E}_{\text {bind }}(\mathrm{Pt}(111))$. Reproduced with permission from ref. [22].

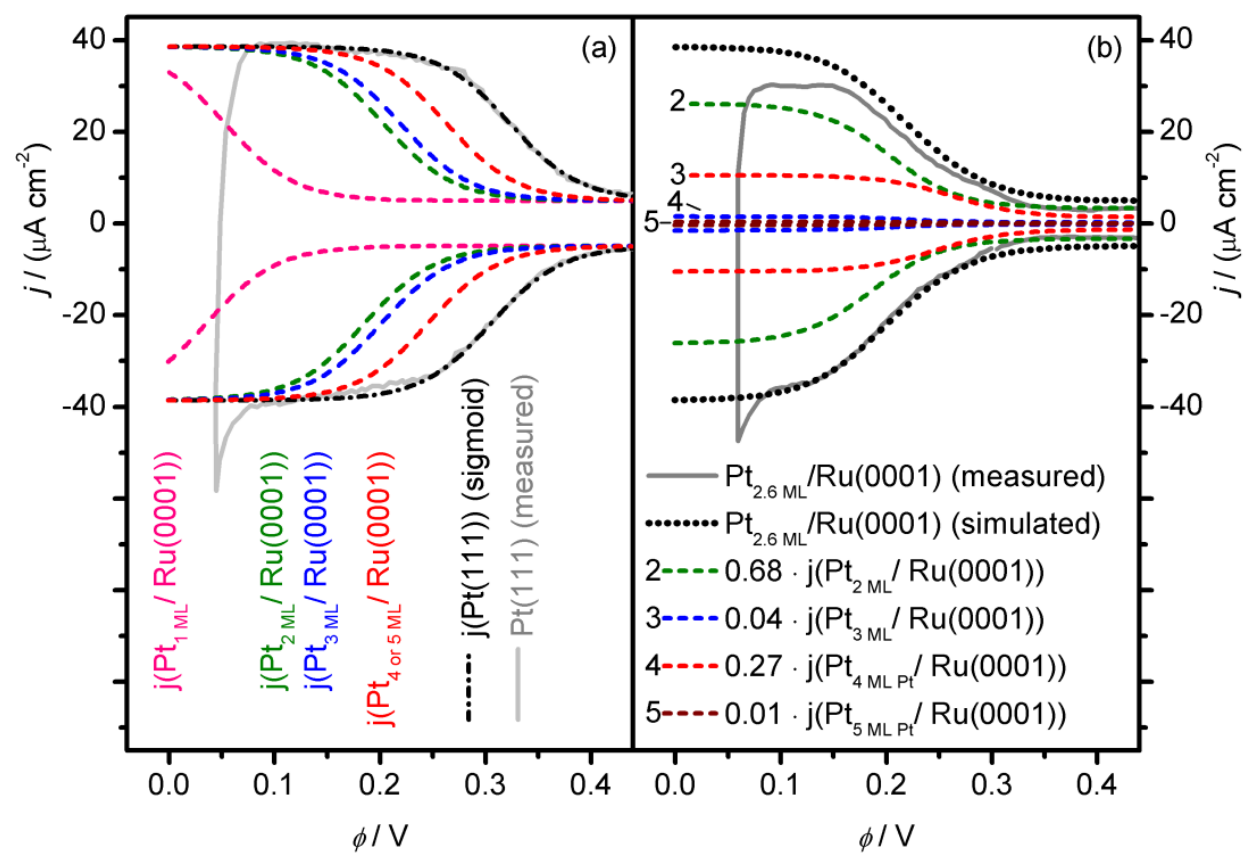

Figure 3-8. (a) solid line: upd- $\mathrm{H}_{\mathrm{ad}}$ region of the voltammogram of $\mathrm{Pt}(111)$ (see Figure 3-6 k); dash-dotted line: $\mathrm{j}(\mathrm{Pt}(111))=$ sigmoidal fit to the $\mathrm{Pt}(111)$ voltammogram; dashed lines: simulated voltammograms for $\mathrm{Pt}_{\mathrm{n}}$ $\mathrm{ML} / \mathrm{Ru}(0001)$ with $\mathrm{n}=1 \ldots 5$, obtained by shifting $\mathrm{j}(\mathrm{Pt}(111))$ by $-\Delta \mathrm{E}_{\text {bind }}$ (see text and Figure 3-7). (b) solid line: upd$\mathrm{H}_{\mathrm{ad}}$ region of $\mathrm{Pt}_{2.6 \mathrm{ML}} / \mathrm{Ru}(0001)$ (see Figure 3-6n); dotted line: simulation of the upd- $\mathrm{H}_{\mathrm{ad}}$ region as a weighted sum of curves from (a) using weight factors from Figure 3-6i; dashed lines: contributions of the different Pt layer thicknesses to the overall voltammogram. Reproduced with permission from ref. [22]. 
The predictions of the CVs are based on the following simple concept. For a given $\mathrm{H}_{\mathrm{ad}}$ coverage, the equilibrium potential of the reaction $\mathrm{H}^{+}+\mathrm{e}^{-} \rightleftharpoons \mathrm{H}_{\mathrm{ad}}$ is directly linked to the adsorption energy of $H_{a d}$ on the respective surface. This means, if the binding energy decreases by $\Delta E_{\text {bind }}=0.05 \mathrm{eV}$ from surface $A$ to surface $B$, the potential must be shifted by $\Delta \phi=-0.05 \mathrm{~V}$ on surface $\mathrm{B}$ to stabilize the same $\mathrm{H}_{\mathrm{ad}}$ coverage as on surface $\mathrm{A}$. According to Le Chatelier's principle, this just means using a more negative potential to shift the equilibrium $\mathrm{H}^{+}+\mathrm{e}^{-} \rightleftharpoons \mathrm{H}_{\mathrm{ad}}$ to the right hand side. The resulting procedure of simulating the CVs is demonstrated in Figure 3-8. A sigmoidal curve fitted to the $\operatorname{Pt}(111)$ region is shifted by the potential differences $\Delta \phi=-\Delta E_{\text {bind }}\left(\Delta E_{\text {bind }}\right.$ : see Figure 3-7, axis on the right-hand side). A weighted sum of these shifted curves is used as prediction for the voltammograms of the respective model surfaces. The thickness histograms in Figure 3-6 $\mathrm{f}-\mathrm{j}$ are used as weighting factors in each simulation. As visible for $\mathrm{Pt}_{2.6 \mathrm{~mL}} / \mathrm{Ru}(0001)$ in Figure 3-8 and for all other model surfaces in Figure 3-6 k-0, all simulations agree well with the measured curves.

This analysis demonstrates a high predictive capability of DFT calculations, even without explicit consideration of the electrochemical conditions. By analogy with the analysis of $\mathrm{CO}$ adsorption at the solid/gas interface, the high level of quantitative agreement between experiment and theory became possible by involving a well-defined experimental anchor point, from where the behaviour of other surfaces can be incrementally extrapolated. Though this is not exactly an ab-initio prediction, the approach suits studies that aim at a fine-tuning of an already good catalyst material by subtle changes in its composition or structure. The second essential pre-requisite for this accuracy is control of the composition and structure of the model surfaces through their growth in UHV, which ensures that the experimentally studied systems actually match those considered in the calculations. Last but not least, the loop could only be closed by including the quantitative STM image data (Figure 3-6 $f-j$ )

\subsection{Foreign metal islands and surface alloys: ensemble effects and bifunctional mechanism in the Pt-Ru system}

\subsubsection{Pt-Ru: history and model systems}

PtRu catalysts have become the state-of-the-art anode catalyst in Polymer Electrolyte Fuel Cells (PEFCs) operated by CO containing fuel gases [113], as they result, e.g., from steam reforming of hydrocarbons or alcohols [45], or in direct methanol fuel cells (DMFCs) [47]. Pt is usually considered as the primary electrocatalyst, whose activity is obstructed by slowly reacting poisons or intermediates. Ru is then introduced as the modifier to provide an oxygen containing species at low 
potentials to remove $\mathrm{CO}$ by electrooxidation in a bifunctional mechanism $[114,149]$. Most of the related experimental model studies were performed on bulk alloy substrates $[2,34,116,150-153]$ or on bimetallic electrode surfaces prepared by electrochemical or electroless deposition of Ru on Pt(111) $[114,149,154-159]$ or Pt on Ru(0001) [160-164] substrates, respectively. Here, we will give a brief overview of the interplay of Pt and Ru on a bimetallic electrode surface from a different point of view, summarizing findings from refs. $[125,99,165]$.

Certain adsorption and reaction processes on $\mathrm{Ru}(0001)$ are catalytically accelerated by $\mathrm{Pt}$ modifications, and the adsorption of some key species shows preferences for certain atomic ensembles. In the first of the following two sections, the effect of Pt on the formation of $\mathrm{H}_{\mathrm{ad}}$ and $\mathrm{OH}_{\mathrm{ad}}$ layers will be highlighted. A special focus will be on structure effects on adsorption, comparing Pt islands on $\mathrm{Ru}(0001)$ (Figure 3-9a) on the one hand and $\mathrm{Pt}_{x} \mathrm{Ru}_{1-x} / \mathrm{Ru}(0001)$ (Figure 3-9b-d) surface alloys on the other. The island morphologies were fabricated the same way as the Pt films (Figure 3-6a - e) discussed above, just using smaller Pt doses (shorter time and/or slower evaporation rate). Surface alloys resulted from annealing of the island morphologies to temperatures that allow intermixing of the foreign metal atoms and the substrate atoms in the outermost layer.

In Pt/Ru(0001), as in many other systems, surface alloys are actually thermodynamically more stable than the island morphologies $[29,120,166]$. This can be experimentally demonstrated by burying them under an additionally evaporated layer of substrate metal (here: Ru). If the overgrown surface alloy is annealed again, it will float back to the surface [120]. In a simplified picture, this is driven by a lower surface energy of the guest as compared to the host metal atoms. A hint for that is already implied in Figure 3-9: initially, 0.5 ML Pt islands cover the surface. After annealing, the island morphology has totally changed. Zooming in (c and d), 50\% of the atoms appear "dark" (Pt). This is the same on the terraces (c) and on the islands (d), which is only possible if, despite the change in morphology, no Pt is "buried" under the islands. See ref [120] or [29] for details on the mechanism. Stable surface alloys are predicted [167] and experimentally observed for many other metal combinations (see Figure 3-10 for four additional examples).

Whereas the atom distribution in $\mathrm{PtRu} / \mathrm{Ru}(0001)$ was found to be very close to a random one [168], most other systems show preferences for like (Figure 3-10a-c) or unlike (Figure 3-10d) neighbours. Those preferences can be predicted by DFT $[29,167,169,170]$. As for the stability of surface alloys, we wish to emphasize the following observation: if guest $A$ on host $B$ forms a (meta)stable surface alloy, then guest B on metal A will tend to form a sub-surface alloy, where the guest metal enriches in the first subsurface layer. A precursor of that behaviour is the formation of bilayer 
islands in metal vapour deposition $[119,171]$. For detailed discussions of surface alloys and their stability, see refs. [29,39,166,167] .
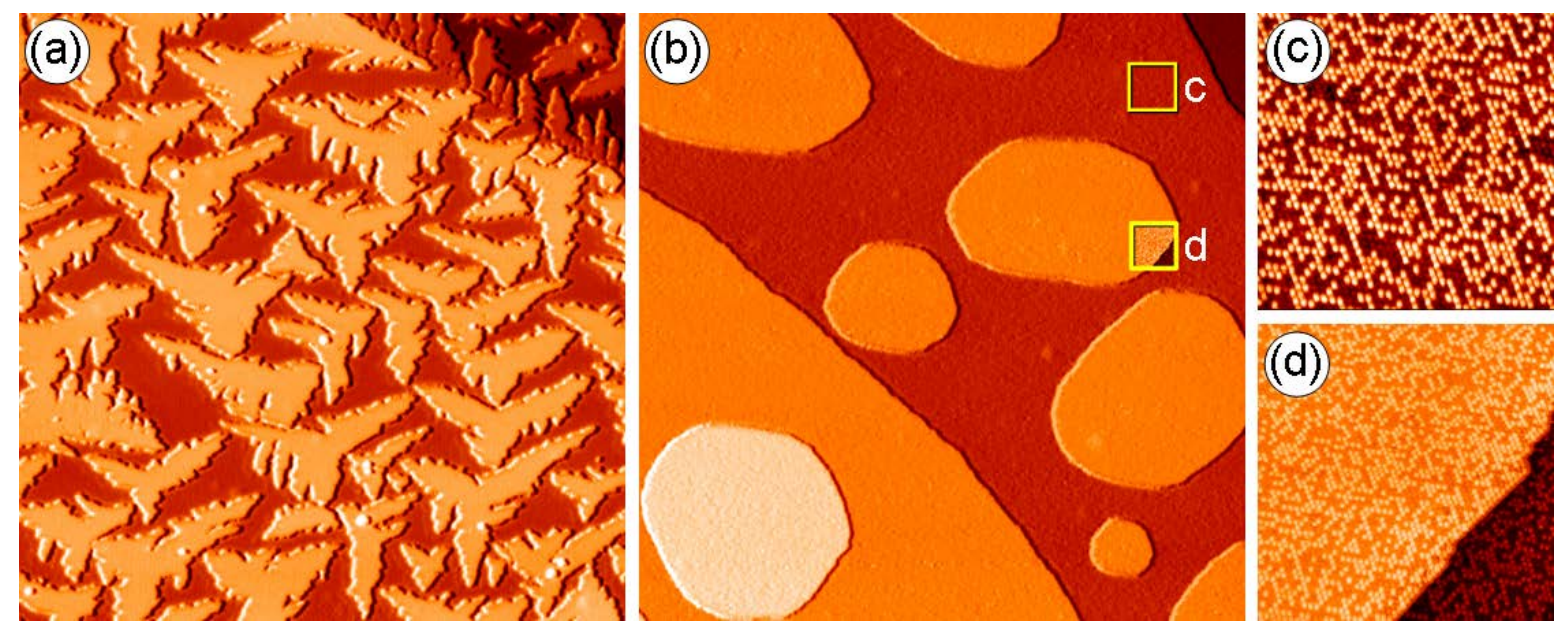

Figure 3-9. (a) and (b) $217 \times 217 \mathrm{~nm}^{2}$ STM images showing the fabrication of a PtRu/Ru(0001) surface alloy [120-122,125,148] as imaged by UHV-STM: (a) 0.5 ML Pt deposited onto Ru(0001) at $300 \mathrm{~K}$. (b) The same surface after annealing to $1350 \mathrm{~K}$. Atomically resolved images of frame size $13 \times 13 \mathrm{~nm}^{2}$ (c) on a large terrace and (d) of an island edge (see frames marked in (b)) showing a $\mathrm{Pt}_{0.5} \mathrm{Ru}_{0.5} / \mathrm{Ru}(0001)$ surface alloy with identical composition on islands and surrounding terraces. Pt atoms appear darker than Ru atoms in the atomically resolved images. Reproduced with permission from ref. [121].

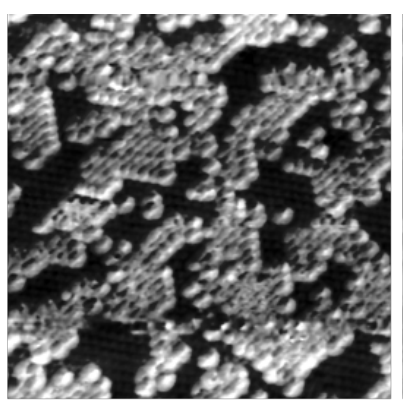

$\mathrm{Pd}_{0.52} \mathrm{Ru}_{0.48} / \mathrm{Ru}(0001)$

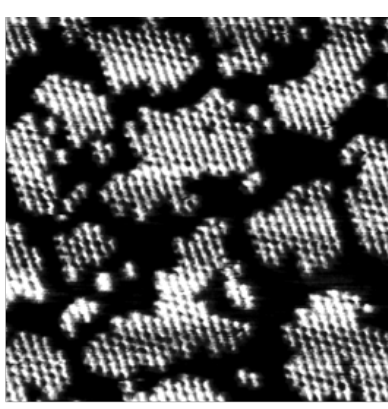

$\mathrm{Ag}_{0.46} \mathrm{Pt}_{0.54} / \mathrm{Pt}(111)$

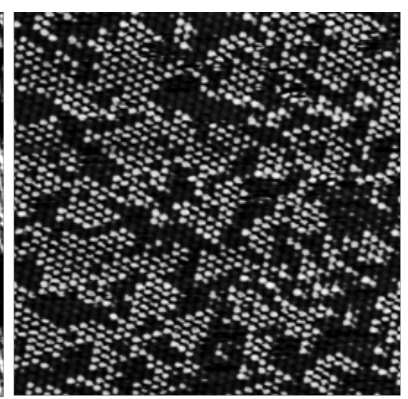

$\mathrm{Au}_{0.44} \mathrm{Pt}_{0.56} / \mathrm{Pt}(111)$

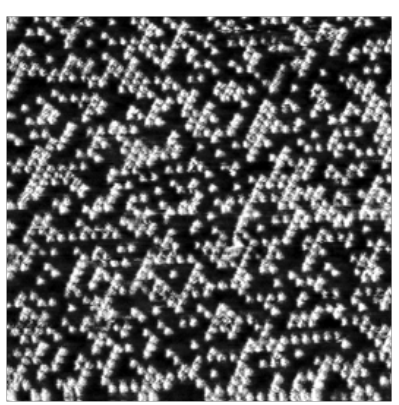

$\mathrm{Ag}_{0.49} \mathrm{Pd}_{0.51} / \mathrm{Pd}(111)$

Figure 3-10. Examples of further surface alloys, imaged by STM with chemical contrast: $\mathrm{Pd}_{0.52} \mathrm{Ru}_{0.48} / \mathrm{Ru}(0001)$ [172], $\mathrm{Ag}_{0.46} \mathrm{Pt}_{0.54} / \mathrm{Pt}(111)\left[29,173\right.$ ], $\mathrm{Au}_{0.44} \mathrm{Pt}_{0.56} / \mathrm{Pt}(111)$ [174], and $\mathrm{Ag}_{0.49} \mathrm{Pd}_{0.51} / \mathrm{Pd}(111)$ [175]. In all images, the atoms of host/guest appear bright/dark, respectively. The frame sizes were $10 \times 10 \mathrm{~nm}^{2}$ in all cases. Reproduced with permission from ref. [29]. 


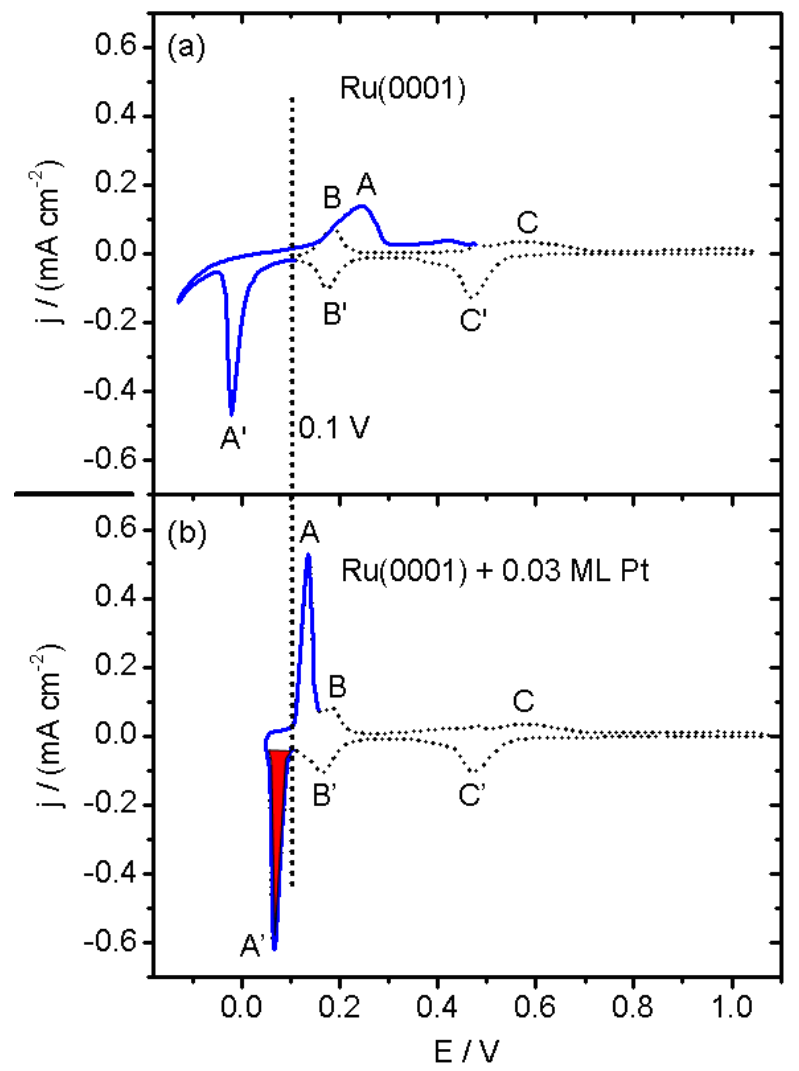

Figure 3-11. Comparison of the base voltammograms for (a) pure Ru(0001) and (b) Ru(0001) modified by 0.03 $\mathrm{ML}$ of Pt islands. The peaks drawn with solid lines belong to the replacement of $\mathrm{OH}_{\mathrm{ad}}$ by upd- $\mathrm{H}_{\mathrm{ad}}$ and vice versa. $50 \mathrm{mV} / \mathrm{s}, 0.1 \mathrm{M} \mathrm{HClO}_{4}$. Reproduced with permission from [165].

\subsubsection{Bifunctional effect reversed: Pt as promoter on $R \mathbf{R}(0001)$}

This section will start with some details about the electrochemical adsorption properties of $\mathrm{Ru}(0001)$. Those are essential to understand the electrocatalytic behaviour of that surface. And their understanding was substantially improved by experiments including UHV-prepared Pt modifications to the $\mathrm{Ru}(0001)$ surface, since those reduced some of the kinetic barriers in forming the potentialdependent adlayers. Figure 3-11a and b show the cyclic base voltammograms of bare and $\mathrm{Pt}$ modified Ru(0001), respectively. As illustrated in Figure 3-12 and explained in more detail in refs. $[125,99,165,176,177]$, the peak couples $B / B^{\prime}$ and $C / C^{\prime}$ are related to the formation and reduction of $\mathrm{OH}_{\mathrm{ad}}$ and $\mathrm{O}_{\mathrm{ad}}$ layers, reaching a coverage of $1 \mathrm{ML} \mathrm{O}_{\mathrm{ad}}$ at the anodic potential limit. On bare $\mathrm{Ru}(0001)$, Peaks $A / A^{\prime}$ are only visible if the scan range is extended to below $0 \mathrm{~V}$. CO displacement experiments indicate that they most likely reflect the replacement of $0.5 \mathrm{ML} \mathrm{OH}$ ad by about $0.5 \mathrm{ML}$ upd- $\mathrm{H}_{\mathrm{ad}}\left(\mathrm{A}^{\prime}\right)$ and vice versa $(A)[165,176,177]$.

The CVs in Figure 3-11 reveal that peaks $B / B^{\prime}$ and $C / C^{\prime}$ are largely unaffected by the presence of Pt. The hysteresis between A and $A^{\prime}$, however, is significantly reduced by Pt islands. $0.1 \mathrm{~V}$ is the 
equilibrium potential for the upd- $\mathrm{H}_{\mathrm{ad}} \leftrightarrow \mathrm{OH}_{\mathrm{ad}}$ exchange process $\left(\mathrm{A} / \mathrm{A}^{\prime}\right)$. At that potential, upd- $\mathrm{H}_{\mathrm{ad}}$ and $\mathrm{OH}_{\mathrm{ad}}$ become metastable against replacement by the other species in the positive and negative going scan, respectively. Since the Pt monolayer islands themselves do not contribute any large voltammetric features (cf. Figure 3-6I) the voltammogram in Figure 3-11b can be considered as $\mathrm{Ru}(0001)$ under the catalytic influence of Pt islands (see Figure 3-12 for an overview and ref. [178] for more details). The key idea is that the upd- $\mathrm{H}_{\mathrm{ad}} \leftrightarrow \mathrm{OH}_{\mathrm{ad}}$ exchange process is slow on bare $\mathrm{Ru}(0001)$ because it takes place through homolytic surface reactions. The bottlenecks in $A^{\prime}$ and $A$ are the electrosorption of $\mathrm{H}_{\mathrm{ad}}$ on an $\mathrm{OH}_{\mathrm{ad}}$-covered surface and the oxidation of $\mathrm{H}_{\mathrm{ad}}$ towards $\mathrm{H}^{+}$at a potential where $\mathrm{H}_{\mathrm{ad}}$ in itself would be stable against $\mathrm{H}^{+}$formation, but gets displaced because $\mathrm{OH}_{\mathrm{ad}}$, once formed, is even more stable.

Pt surface atoms act as channels for the reaction upd- $\mathrm{H}_{\mathrm{ad}} \leftrightarrow \mathrm{H}^{+}+\mathrm{e}^{-}$. In the negative going scan, $\mathrm{H}_{\mathrm{ad}}$ formed at $\mathrm{Pt}$ acts as reductive species to remove $\mathrm{OH}_{\mathrm{ad}}$ by $\mathrm{H}_{2} \mathrm{O}$ formation, whereas in the positive going scan it promotes the formation of $\mathrm{OH}_{\mathrm{ad}}$ via $\mathrm{H}_{2} \mathrm{O}$ dissociation $[125,178]$. Since it originates from an adlayer replacement on the Pt-free Ru areas, the charge in peak $A^{\prime}$ decreases linearly with increasing Pt coverage (Figure 3-13a). Due to the disperse distribution of Pt and Ru (see following section), the charge in peak $A^{\prime}$ decreases faster than linearly with increasing Pt content in surface alloys.

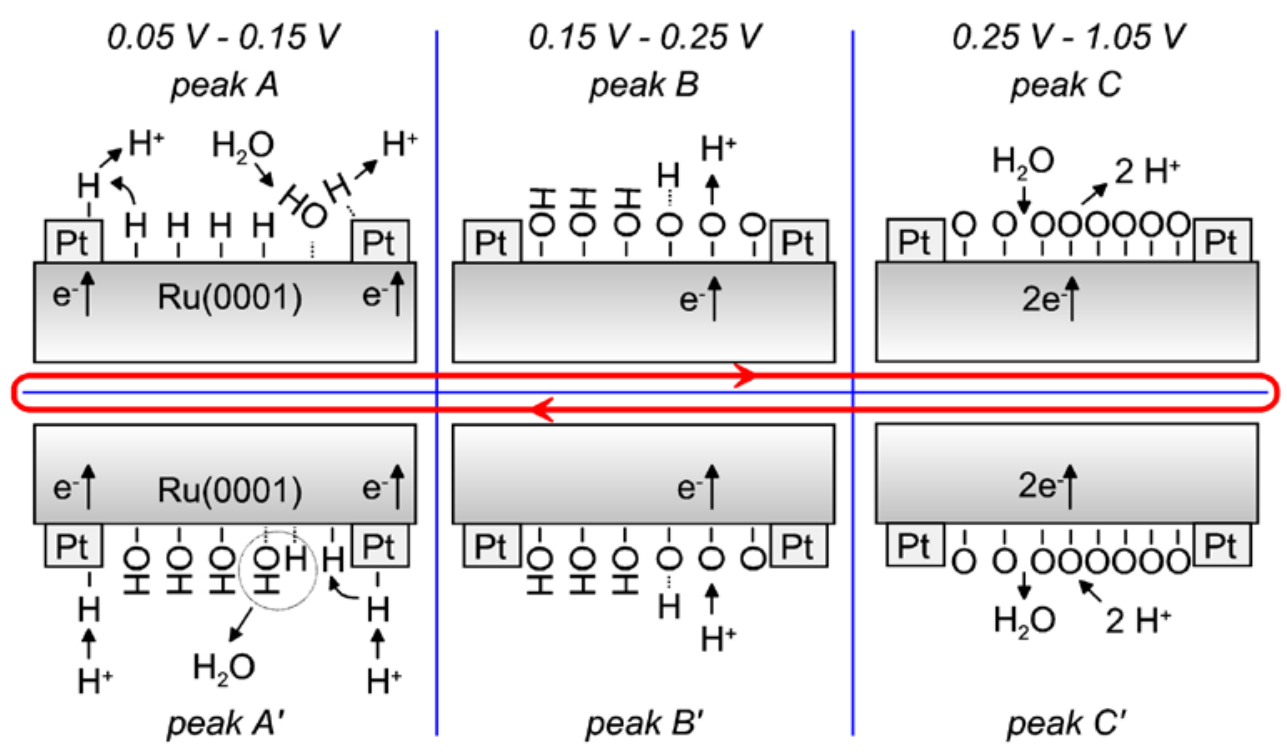

Figure 3-12. Illustration of the formation, removal, and exchange of adlayers on $\mathrm{Ru}(0001)$ in the presence of Pt islands / sites as observed in the peaks $A / A^{\prime}, B / B^{\prime}$, and $C / C^{\prime}$ (see also Figure 3-11). Processes in the anodic / cathodic potential scan direction are shown in the upper / lower part; for simplicity, $\mathrm{H}^{+}$is used instead of $\mathrm{H}_{3} \mathrm{O}^{+}$. Reproduced with permission from ref. [178]. 

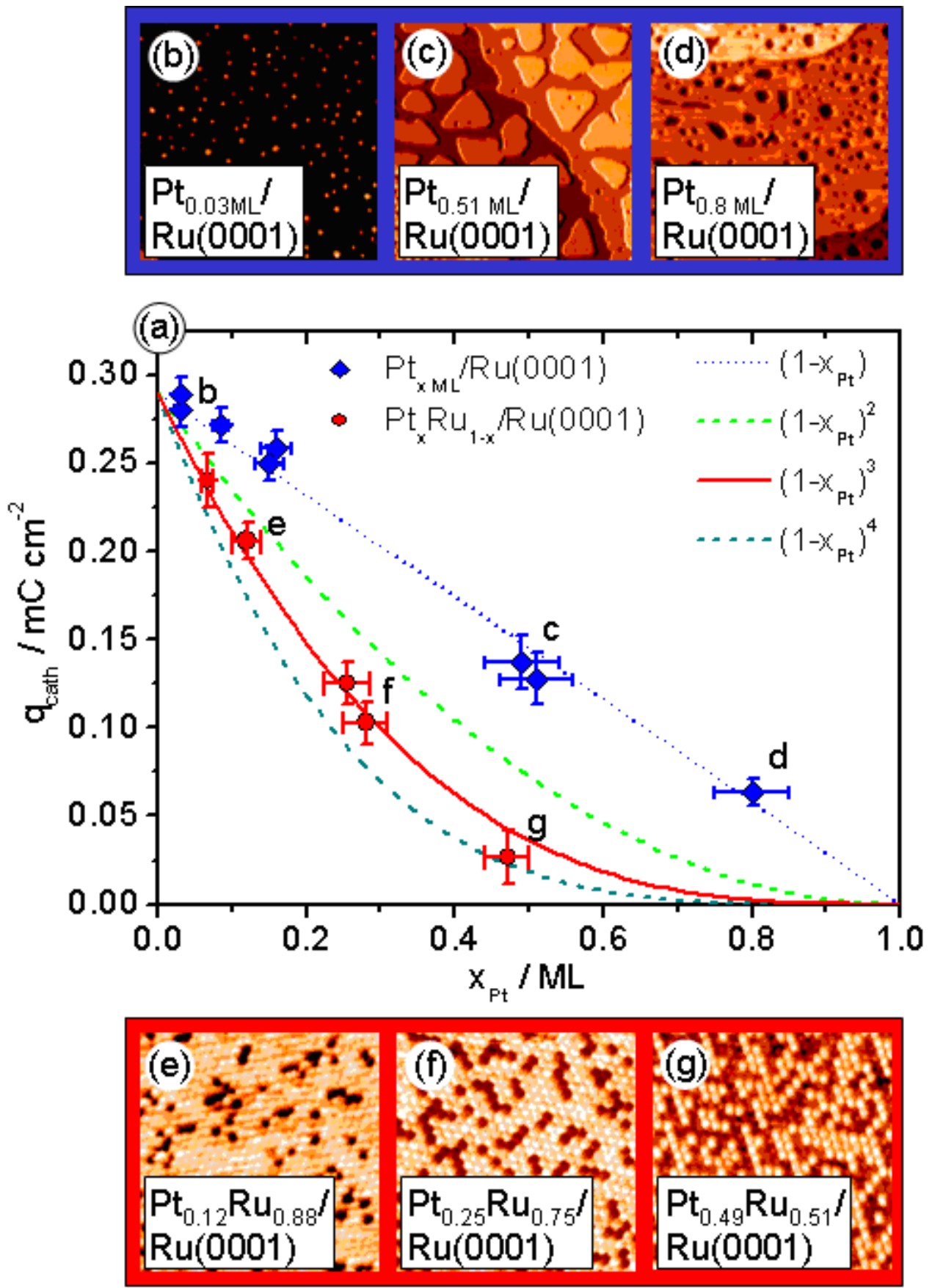

Figure 3-13. (a) Charge in peak A' (see Figure 3-7 b) as a function of Pt surface content; $(\diamond)$ Pt submonolayer islands/films on $\mathrm{Ru}(0001)$; $(\bullet) \mathrm{Pt}_{\mathrm{x}} \mathrm{Ru}_{1-\mathrm{x}} / \mathrm{Ru}(0001)$ surface alloys; lines: predicted trends for linear or parabolic correlations between charge and Pt surface content [179]. (b),(c),(d): STM images showing three different Pt island/film morphologies (frame size $142 \times 142 \mathrm{~nm}^{2}$ ). (e),(f),(g): atomically resolved images of three different surface alloys (frame size $6.5 \times 6.5 \mathrm{~nm}^{2}$ ). The data points belonging to the STM images are labelled in (a). 


\subsubsection{Pt $P u_{1-x} / R u(0001)$ surface alloy electrodes}

As discussed above, surface alloys are ideal model systems of electrodes with chemical heterogeneity on a sub-nm scale. If they resemble the kind of structure illustrated in Figure 1-1h (and many surface alloys actually do [29]), all information about the environment of each surface atom is experimentally accessible: the lateral neighbours through high-resolution STM, and the underlying neighbours because they only consist of the host metal. Figure 3-14 gives an overview of the atom distribution of $\mathrm{Pt}_{x} \mathrm{Ru}_{1-\mathrm{x}} / \mathrm{Ru}(0001)$ surface alloys and their cyclic base voltammograms in $\mathrm{HClO}_{4}$ electrolyte.

The voltammograms in Figure 3-14f - j reveal three main features. First, as mentioned and discussed above, the peak couple $A / A^{\prime}$ is as sharp for a small amount of Pt atoms as it is for a small Pt island coverage (Figure 3-11b). The amplitude of $A / A^{\prime}$ quickly decreases with increasing $\mathrm{Pt}$ content. Second, the overall charge contained in the voltammograms quickly decreases with increasing Pt content. And third, symmetric peak couples $D / D^{\prime}, E / E^{\prime}$, and $F / F^{\prime}$ start evolving at higher Pt contents.

The behaviour of $A / \mathrm{A}^{\prime}$ indicate that $\mathrm{Pt}$ atoms embedded into atomically smooth $\mathrm{Pt}_{\mathrm{x}} \mathrm{Ru}_{1}$. x/Ru(0001) surface alloys catalyse the $\mathrm{OH}_{\mathrm{ad}} \leftrightarrow$ upd- $\mathrm{H}_{\mathrm{ad}}$ exchange the same way that Pt islands on $\mathrm{Ru}(0001)$ do (Figure 3-12). In this case, spill-over comes from neighbouring Pt-rich adsorption ensembles, which at the exchange potential are also free of $\mathrm{OH}_{\mathrm{ad}}$, rather than from Pt monolayer islands. The charge in the sharp voltammetric peaks associated with this adlayer exchange decreases much more rapidly for the $\mathrm{Pt}_{x} \mathrm{Ru}_{1-\mathrm{x}} / \mathrm{Ru}(0001)$ surface alloys than for the Pt monolayer covered $\mathrm{Ru}(0001)$ surface, with the third power of the Ru content rather than linearly. Considering that the Pt surface atoms are essentially randomly distributed on the surface alloy layer [168], this indicates that the characteristic current spike is due $\mathrm{OH}_{\mathrm{ad}} \leftrightarrow$ upd- $\mathrm{H}_{\mathrm{ad}}$ exchange on sites on the $\mathrm{Pt}_{\mathrm{x}} \mathrm{Ru}_{1}$. ${ }_{x} / R u(0001)$ surface alloy. This is consistent with DFT calculations [125] that predict $R u_{3}$ sites to be the most stable ones for $\mathrm{H}$ and $\mathrm{OH}$ on the surface alloys. Their population scales with the third power of the Ru concentration. In the model experiments, the Pt atoms thus play a double role: their weak adsorption makes them the "channel" for faster adlayer exchange through the mentioned spill-over process, and at the same time their presence decreases the number of the most stable adsorption sites, $\mathrm{Ru}_{3}$. 


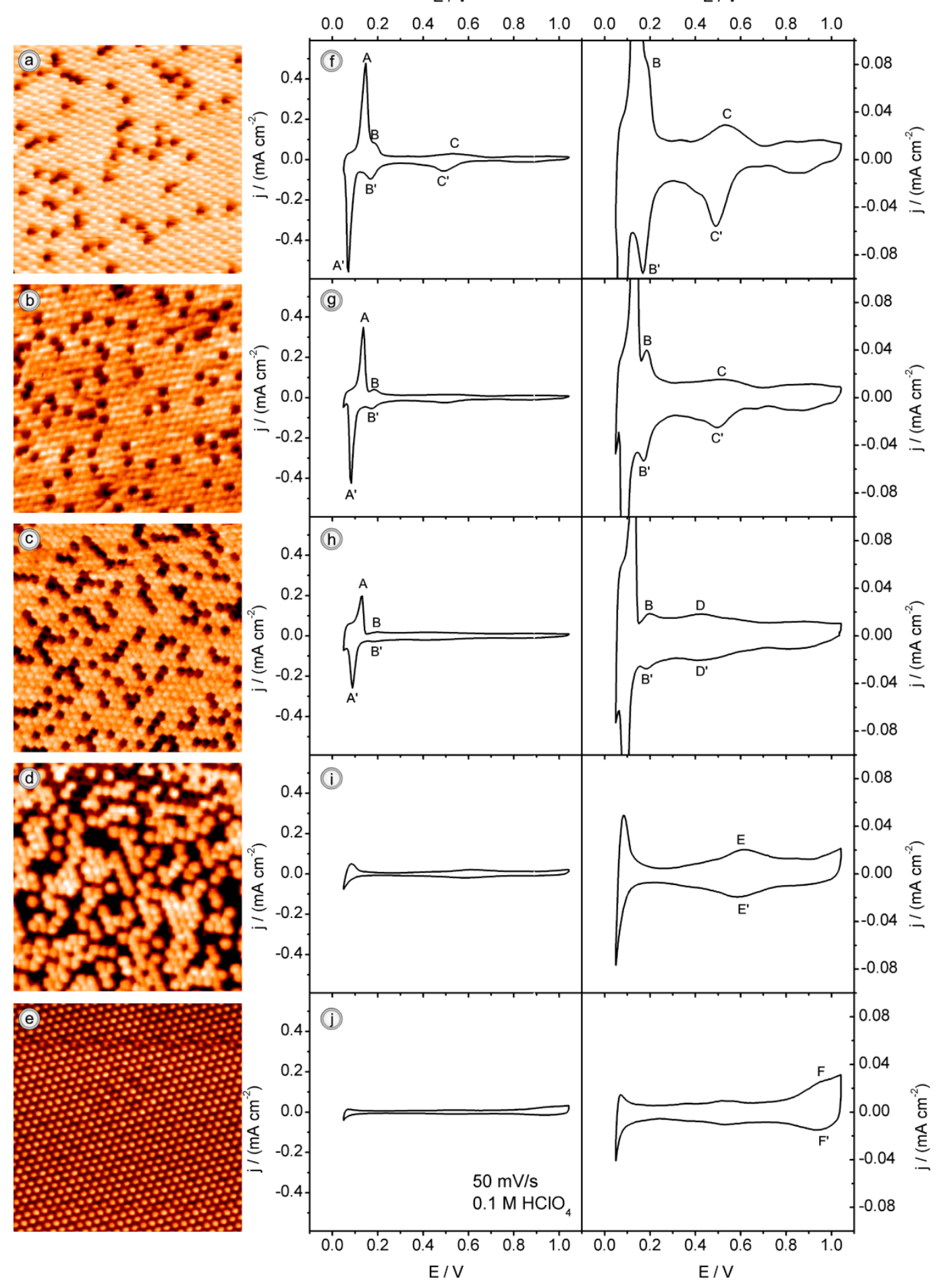

Figure 3-14. STM images (a-e) and corresponding cyclic voltammograms (f-j) of different $\mathrm{Pt}_{\mathrm{x}} \mathrm{Ru}_{1}$. ${ }_{x} / R u(0001)$ surface alloys. Voltammograms on right hand side with expanded current scale. $\left.x_{p t}=a, f\right)$ $0.07, \mathrm{~b}, \mathrm{~g}) 0.12, \mathrm{c}, \mathrm{h}) 0.25, \mathrm{~d}, \mathrm{i}) 0.53, \mathrm{e}$, j) 1.05 (scan speed $50 \mathrm{mV} \mathrm{s}^{-1}$ ). For all STM images, the frame size is $6.5 \times 6.5 \mathrm{~nm}^{2}$. Reproduced with permission from ref. [125]. 
Reversible adsorption of $\mathrm{H}$ and $\mathrm{OH}$ on mixed $\mathrm{Pt}_{2} \mathrm{Ru}$ and $\mathrm{PtRu}_{2}$ sites with lower binding energies compared to $\mathrm{Ru}_{3}$ sites [125] instead results in broad adsorption and desorption features in the potential range between 0.0 and $0.6 \mathrm{~V}\left(\mathrm{D} / \mathrm{D}^{\prime}\right.$ and $\left.\mathrm{E} / \mathrm{E}^{\prime}\right)$, while adsorption on $\mathrm{Pt}_{3}$ sites is very weak and hardly detectable for hydrogen and sets in only at very anodic potentials $>0.8 \mathrm{~V}$ for $\mathrm{OH}$ (peaks F/F'). These observations are in perfect agreement with results of previous thermal desorption experiments [180], which showed $\mathrm{H}_{2}$ desorption peaks from the surface alloys at temperatures between those of pure Ru(0001) and a Pt monolayer covered Ru(0001) surface.

The versatility of sites with varying local adsorption strengths for electrocatalytically relevant reactants and intermediates makes $\mathrm{Pt}_{x} \mathrm{Ru}_{1-\mathrm{x}} / \mathrm{Ru}(0001)$ surface alloys highly active for key reactions such as oxygen reduction [37] or CO oxidation $[99,181,182]$. As will be highlighted in the following section, even model surfaces that were not intentionally designed as surface alloys may actually owe any observed catalytic enhancement to a few "active sites" with tuned adsorption energies due to ligand or mixed ensemble effects. Those sites result from spontaneous (as typical for systems like $\mathrm{Pt} / \mathrm{Au}(111)[29,94,183]$ or electrochemically induced $[181,182]$ formation of surface alloy patches, driven by their higher thermodynamic stability as compared to foreign metal islands [166].

\subsection{Stability of bimetallic model surfaces under electrochemical conditions}

Preparation of model surfaces through controlled vapour deposition in combination with annealing is obviously a strong tool to demonstrate or verify specific atomistic picture effects or hypotheses in electrocatalysis. But even if the control of the surface structure and composition is excellent just after the preparation, there is no guarantee that the surface will not change its morphology and/or composition once exposed to the solid/liquid interface and the potential control [184]. Here, we will highlight some recent work performed on the $\mathrm{Pt} / \mathrm{Ru}(0001)$ system that clearly shows how the extension of the electrochemical potential beyond a certain threshold can lead to electrochemically relevant changes in the surface morphology $[98,181]$. Figure 3-15 demonstrates the effect of potential cycling on a Ru(0001) surface covered by $0.32 \mathrm{ML}$ of Pt. The dashed line in Figure $3-15 a$ is the base $\mathrm{CV}$ of bare $\mathrm{Ru}(0001)$ in sulphuric acid electrolyte. Note that the peaks $\mathrm{A} / \mathrm{A}^{\prime}$ and $B / B^{\prime}$, that are characteristic for $\mathrm{Ru}(0001)$ in perchloric acid solution (Figure 3-11a), are not visible here. This is a well-known phenomenon [178] and it is assumed to be due to the strong specific adsorption of (bi-)sulphate species [185] that competes with and suppresses $\mathrm{H}_{\mathrm{ad}}$ formation and only becomes displaced in the anodic scan at potentials beyond $0.5 \mathrm{~V}$. Similar behaviour can be observed when cycling in $\mathrm{CO}$ saturated perchloric acid solution. 

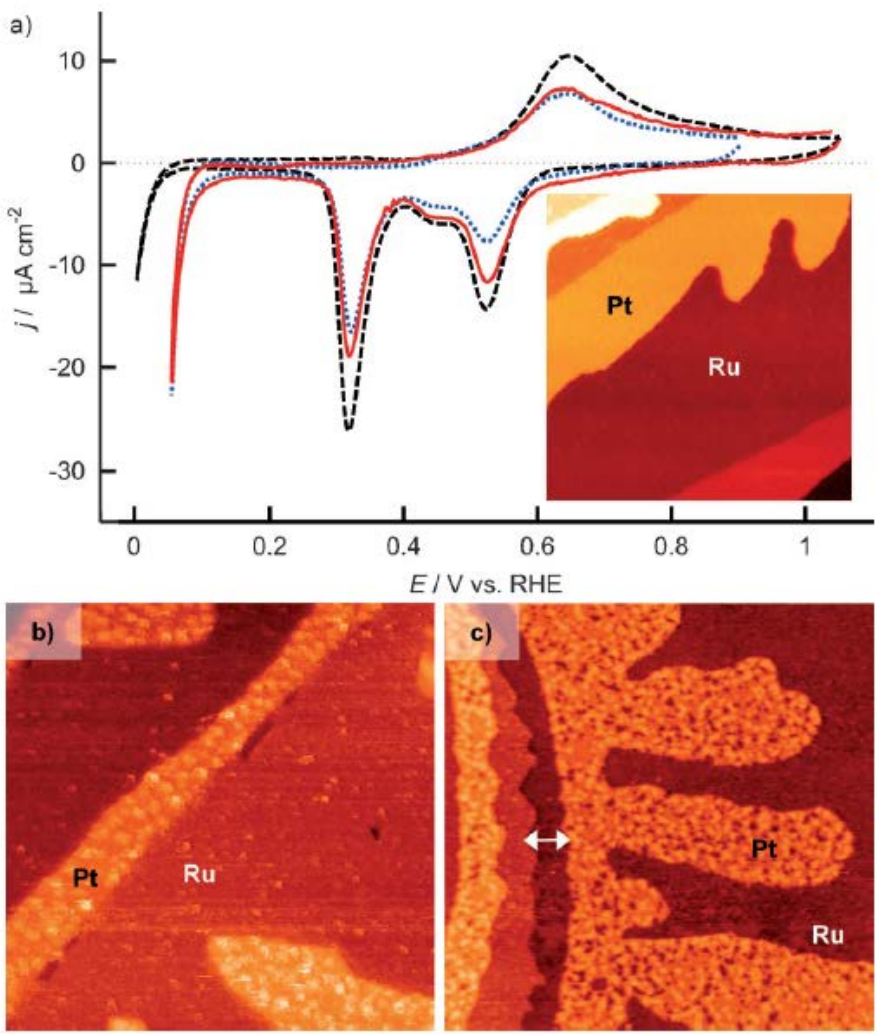

Figure 3-15. (a) CV recorded at $10 \mathrm{mVs}^{-1}$ and in $0.5 \mathrm{M} \mathrm{H}_{2} \mathrm{SO}_{4}$ for $\mathrm{Ru}(0001)$ (black, dashed line), $0.32 \mathrm{ML}$ $\mathrm{Pt} / \mathrm{Ru}(0001)$ (blue dotted line), and 0.40 ML Pt/Ru(0001) (red line); inset: STM image (200 x $200 \mathrm{~nm}^{2}$ ) of 0.32 ML Pt / Ru(0001) just after preparation. (b,c) STM images $\left(200 \times 200 \mathrm{~nm}^{2}\right)$ of the electrode after potential cycling up to $0.9 \mathrm{~V}$ (b) and $1.05 \mathrm{~V}$ (c). Reproduced with permission from ref. [181].

For the Pt covered surface, the most important features in the STM images are the Pt decorations along the Ru step edges. The two respective CVs show overall reduced current amplitude, in agreement with the previous observation that the Pt monolayer areas are essentially featureless (see Figure 3-6 I) and the CV essentially reflects a down-scaled Ru(0001) profile, similar to the trend discussed in Figure 3-13. The extension of the scan range from $0.9 \mathrm{~V}$ to $1.05 \mathrm{~V}$ leads to more oxidation charge in the anodic scan, and the reduction peak in the subsequent cathodic scan grows accordingly. The same behaviour would also be expected for a Pt-free Ru(0001), i.e., no sign for any morphology changes are visible in the CV. Comparing STM probed morphologies before and after cycling, however, reveals an obvious influence of the anodic potential limit reached in the CVs: whereas the morphology remains essentially untouched after cycling up to $0.9 \mathrm{~V}$ (Figure 3-15b) one atomic layer deep trenches have formed in the Ru surface just behind the Pt decorations (Figure 3-15c) after cycling to $1.05 \mathrm{~V}$. If all changes in the morphology were restricted to dissolution of Ru atoms from behind the Pt step decorations, the electrochemical properties of the surface should remain largely unaffected, since the dissolving Ru atoms mainly unveil the underlying Ru layer, which would be a zero-sum game with respect to the surface fraction of Pt and Ru. That (false) assumption 
would be supported by the largely unaffected base CV. Using the electrochemical oxidation of $\mathrm{CO}$ as a probe reaction, however, reveals that the surface restructuring induced by reaching $1.05 \mathrm{~V}$ indeed has an effect on the electrocatalytic properties.

Figure 3-16 shows an experiment similar to the one in Figure 3-15, but in a flow of CO-saturated electrolyte. The bare $\mathrm{Ru}(0001)$ surface is essentially inactive for $\mathrm{CO}$ oxidation, which is a welldescribed effect of the high coverage by strongly adsorbed $\mathrm{O}_{a d}$ species that prohibit $\mathrm{CO}$ adsorption [177]. If the potential range is kept below $0.9 \mathrm{~V}$, the presence of Pt islands on the surface slightly improves the activity (dashed line in Figure 3-16), but it is still much worse than the activity of a PtRu surface alloy (dash-dotted line) in the same potential range. If the Pt island covered surface is cycled to $1.05 \mathrm{~V}$, however, the activity significantly improves (dotted line in Figure 3-16). The STM image after cycling to $1.05 \mathrm{~V}$ (Figure 3-16c) reveals the formation of a gap behind the Pt step decoration similar to the one in Figure 3-15c. The improved activity for $\mathrm{CO}$ oxidation could not be explained if this were the only change to the surface structure. It was concluded that the missing Ru atoms intermixed with the Pt deposit, thus forming the mixed $\mathrm{Ru}_{2} \mathrm{Pt}$ and $\mathrm{RuPt}_{2}$ adsorption sites with adsorption energies for $\mathrm{CO}$ and $\mathrm{O}$ that are lower than those of $\mathrm{Ru}_{3}$ sites and higher than those of the $\mathrm{Pt}_{3}$ sites (see discussion of Figure 3-14).

These results show the importance of thorough surface structure analysis with methods that are able to probe the lateral atom distribution in model surfaces, i.e., STM with chemical contrast. Even if no "post-mortem" analyses of the atom distribution of surfaces as in Figure 3-15c or Figure 3-16c have been reported so far, the "missing" Ru atoms in combination with the knowledge about the electrochemical behaviour of purpose-prepared surface alloys allows reasonable conclusions to be drawn.

As to the bifunctional effect in the Pt-Ru system, one has to conclude that mixed adsorption sites with intermediate bonding power as compared to pure Pt or Ru are likely to play an essential role for the overall activity. Previous studies (e.g., [99]), that have discussed the electrocatalytic effects based only on an observed or assumed island morphology without atomic scale intermixing, may have to be revised. Model studies involving closed mono- and multilayers of just one deposit that effectively bury the substrate (e.g., Figure 3-6) $[22,139,140]$, on the other hand, are less likely to be affected by unexpected intermixing since alloying takes place only if both metals are exposed. Furthermore, surface alloys themselves seem to be less sensitive to unexpected restructuring [182], which can be rationalized by their higher thermodynamic stability as compared with foreign metal islands $[29,168]$. 

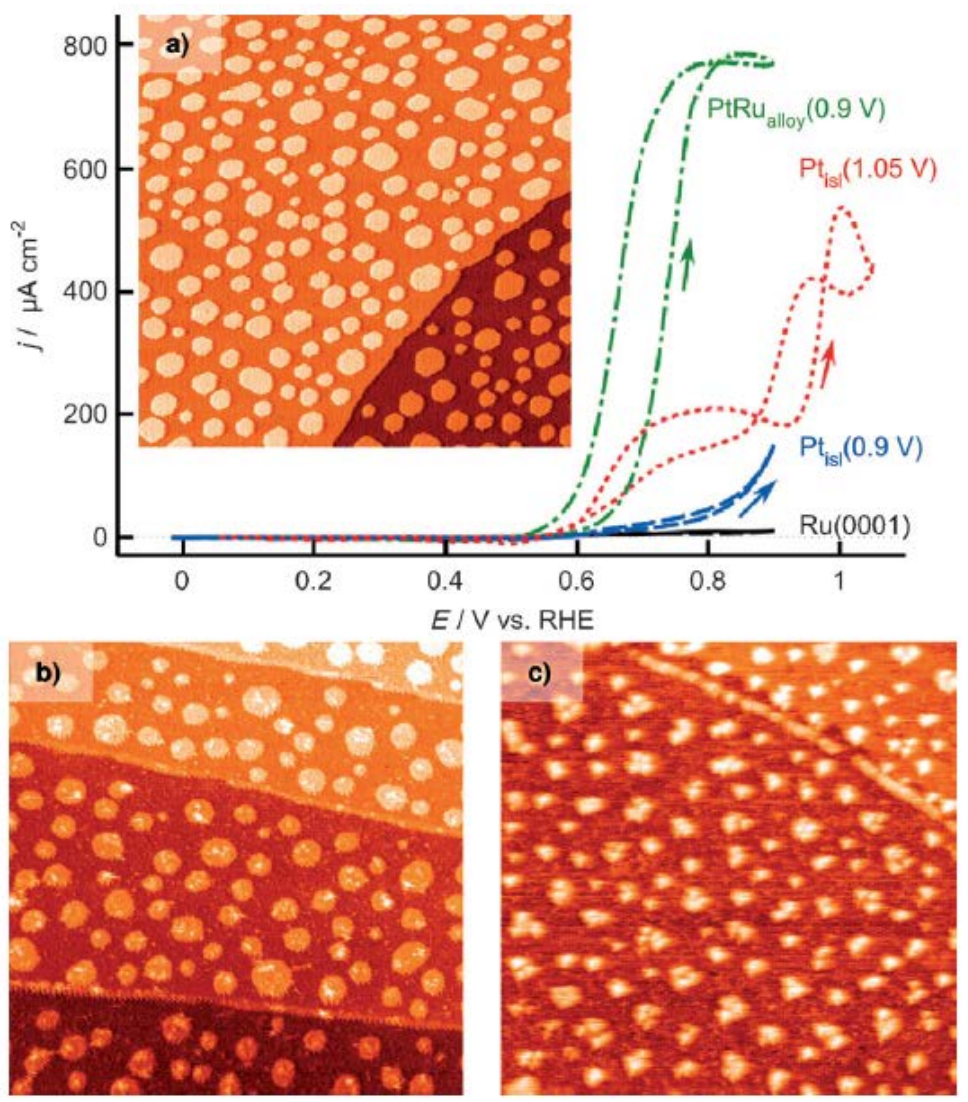

Figure 3-16. (a) Potentiodynamic bulk $\mathrm{CO}$ oxidation in $0.5 \mathrm{M} \mathrm{H}_{2} \mathrm{SO}_{4}$ at $10 \mathrm{mVs}^{-1}$ on $\mathrm{Ru}(0001)$ (black line), $\mathrm{Pt}_{0.29 \mathrm{ML}} / \mathrm{Ru}(0001)$ potential-cycled up to $0.9 \mathrm{~V}$ (blue dashed line), $\mathrm{Pt}_{0.39 \mathrm{ML}} / \mathrm{Ru}(0001)$ cycled up to $1.05 \mathrm{~V}$ (red dotted line), and a $\mathrm{Pt}_{0.3} \mathrm{Ru}_{0.7} / \mathrm{Ru}(0001)$ surface alloy potential cycled up to $0.9 \mathrm{~V}$ (green, dashed-dotted line). Arrows indicate the anodic scan. The inset shows the as-prepared electrode with 0.28 ML Pt deposited on $\operatorname{Ru}(0001)\left(200 \times 200 \mathrm{~nm}^{2}\right)$. (b,c) STM images $\left(200 \times 200 \mathrm{~nm}^{2}\right)$ of the electrodes after potential cycling up to 0.9 $\mathrm{V}(\mathrm{b})$ and $1.05 \mathrm{~V}$ (c). Reproduced with permission from ref. [181].

\section{Summary and Outlook}

Surface science insights gained in UHV experiments and related ab-initio studies brought research in electrocatalysis to another level. Interfacial electrochemistry has relied upon microscopic pictures from its very beginning, but the ever increasing accuracy of experimental adsorption and reaction data obtained at the solid-gas interface substantially helped to fill many previous "wildcard" assumptions with more reference points. Whereas many early studies assumed that the adlayers formed at the solid/liquid interface must necessarily differ substantially from those at the solid/gas interface due to the influences of water, electrolyte, and electrochemical potential, experiments specifically looking at both interfaces found surprisingly many similarities. We exemplarily showed 
the examples of $\mathrm{CO}$ on $\mathrm{Pt}(111)$ (measured at both surfaces) and $\mathrm{H}$ on $\mathrm{Ru}(0001)$ (where the UHVprepared adlayers and their desorption are consistent with electrochemical data).

We also highlighted many examples of coupled UHV/electrochemistry experiments. Whereas historically, UHV-based methods were first used for ex-situ analyses of electrodes that were transferred into vacuum, more recent studies made increasing use of UHV-based surface preparation recipes. Starting with the cleaning and annealing of bulk alloys, which we illustrate through the example of $\mathrm{Pt}_{3} \mathrm{Sn}(111)$, UHV-prepared model electrodes made use of controlled metal film growth and surface alloy formation, very much in line with concomitant studies in the surface science community. We illustrate that with the examples of Pt films and PtRu surface alloys on $\mathrm{Ru}(0001)$, which were extensively studied at the solid/gas and the solid/liquid interface, along with and inspired by ab-initio predictions about their (electro-)chemical and (electro-)catalytic properties.

Whereas UHV preparation turned out to be ideal to design experiments that match the slab-type model systems typically studied in DFT studies, we also flag the necessity of verifying the actual surface structure before and after any electrochemical experiments. Surface alloys often are thermodynamically more stable than foreign metal islands. Even if higher temperatures are required in UHV to activate metal place exchange processes for surface alloy formation, the electrochemical potential and the related adsorbates may also enable atomic-scale intermixing. If such "local" surface alloys are electrocatalytically superior, a few accidentally created active sites may dominate the outcome of electrocatalytic experiments (such as HER/HOR, ORR, or CO oxidation), and neglecting them may lead to false conclusions. The only safe way to rule out such "accidental" active site formation would be the purpose-preparation of surface alloys of the respective system through annealing and to confirm that they are not active. If they are active, they may potentially influence experiments that actually aim to elucidate the properties of foreign metal islands.

The high flexibility of accessible model surfaces and the ever growing knowledge about adsorption and reaction at the solid/gas interface will trigger much more UHV/electrochemistry research in the near future. The growing maturity of the respective experimental setups will come with an increased use of in-situ analysis methods, such as collector electrodes, on-line mass spectrometry, or vibrational spectroscopy. Electrochemical in-situ STM at UHV-prepared surfaces may be a suitable tool to track potential-induced morphology changes. Beyond metal electrodes, we are likely to see similar approaches for tailor-made thin-film oxides or organic model electrodes. The symbiosis of UHV(-STM) and electrochemistry has a bright future ahead. 


\section{References}

[1] D. Kolb, Zeitschrift Für Phys. Chemie 154 (1987) 179-199.

[2] N. Marković, P.N. Ross, Surf. Sci. Rep. 45 (2002) 117-229.

[3] J. Clavilier, R. Faure, G. Guinet, R. Durand, J. Electroanal. Chem. Interfacial Electrochem. 107 (1979) 205-209.

[4] J. Leddy, V. Birss, P. Vanysek, Historical Perspectives on the Evolution of Electrochemical Tools, The Electrochemical Society, 2004.

[5] M.P. Soriaga, D.A. Harrington, J.L. Stickney, A. Wieckowski, in:, B.E. Conway, J.O. Bockris, R.E. White (Eds.), Mod. Asp. Electrochem., Plenum Press, New York, 1996.

[6] J.O. Bockris, A.K.N. Reddy, M. Gamboa-Aldeco, Modern Electrochemistry, Kluwer, 2002.

[7] N.M. Markovic, P.N. Ross, Surf. Sci. Rep. 45 (2002) 121-229.

[8] H.E. Hoster, H.A. Gasteiger, in:, Handb. Fuel Cells - Fundam. Technol. Appl., 2003.

[9] A.S. Homa, E. Yeager, B.D. Cahan, J. Electroanal. Chem. Interfacial Electrochem. 150 (1983) 181-192.

[10] A.T. Hubbard, J.Y. Gui, J. Chim. Phys. 88 (1991) 1547-1590.

[11] J.H. Sinfelt, Bimetallic Catalysts: Discoveries, Concepts and Applications, Wiley, New-York, 1983.

[12] C.T. Campbell, in:, G. Ertl, H. Knözinger, J. Weitkamp (Eds.), Handb. Heterog. Catal., WileyVCH, Weinheim, 1997, pp. 814-826.

[13] W. Yu, M.D. Porosoff, J.G. Chen, Chem. Rev. 112 (2012) 5780-5817.

[14] V. Ponec, Appl. Catal. A Gen. 222 (2001) 31-45.

[15] D.S. Strmcnik, D. V Tripkovic, D. van der Vliet, K.-C. Chang, V. Komanicky, H. You, G. Karapetrov, J.P. Greeley, V.R. Stamenkovic, N.M. Marković, J. Am. Chem. Soc. 130 (2008) 15332-15339.

[16] P.N. Ross, in:, J. Lipkowski, P.N. Ross (Eds.), Electrocatalysis, Wiley-VCH, New York, 1998, pp. 43-74.

[17] J.E. Mueller, P. Krtil, L. a Kibler, T. Jacob, Phys. Chem. Chem. Phys. 16 (2014) 15029-42.

[18] M. Mavrikakis, B. Hammer, J.K. Nørskov, Phys. Rev. Lett. (1998) 2819-2822.

[19] A. Schlapka, M. Lischka, A. Groß, U. Käsberger, P. Jakob, Phys. Rev. Lett. 91 (2003) 016101.

[20] A. Gross, Top. Catal. 37 (2006) 29-40.

[21] A. Gross, J. Comput. Theoret. Nanosci. 5 (2008) 894-922.

[22] H.E. Hoster, O.B. Alves, M.T.M. Koper, ChemPhysChem 11 (2010) 1518-24.

[23] M. Gsell, Science 280 (1998) 717-720.

[24] B. Hammer, Y. Morikawa, J.K. Nørskov, Phys. Rev. Lett. (1996) 2141-2144.

[25] W.M.H. Sachtler, in:, G. Ertl, H. Knözinger, J. Weitkamp (Eds.), Handb. Heterog. Catal., VCHWiley, Weinheim, 1997, pp. 1077-1084.

[26] Y. Soma-Noto, W.M.H. Sachtler, J. Catal. 32 (1974) 315-324.

[27] S. Sakong, C. Mosch, A. Gross, Phys. Chem. Chem. Phys. 9 (2006) 2216-2225.

[28] J.G. Chen, C.A. Menning, M.B. Zellner, Surf. Sci. Rep. 63 (2008) 201-254. 
[29] H.E. Hoster, "Properties of Surface Alloys" in "Surface and Interface Science, Vol. 3: Properties of Composite Surfaces: Alloys, Compounds, Semiconductors", K. Wandelt (ed.); John Wiley \& Sons: 2014; Chapter 12, pp. 61 - 99

[30] M.P. Mercer, D. Plana, D.J. Fermín, D. Morgan, N. Vasiljevic, Langmuir 31 (2015) 1090410912.

[31] H. Lv, D. Li, Y. Kang, D. Strmcnik, N.M. Markovic, V.R. Stamenkovic, this special issue

[32] Y. Gauthier, R. Baudoing-Savois, J.M. Bugnard, W. Hebenstreit, M. Schmid, P. Varga, Surf. Sci. 466 (2000) 155-166.

[33] V.R. Stamenkovic, B.S. Mun, M. Arenz, K.J.J. Mayrhofer, C.A. Lucas, G.F. Wang, P.N. Ross, N.M. Markovic, Nat. Mater. 6 (2007) 241-247.

[34] H.E. Hoster, T. Iwasita, H. Baumgärtner, W. Vielstich, Phys. Chem. Chem. Phys. 3 (2001) 337346.

[35] H.A. Gasteiger, P.N. Ross, E.J. Cairns, Surf. Sci. 293 (1993) 67-80.

[36] B. Fowler, C. Lucas, A. Omer, G. Wang, V. Stamenkovic, N. Markovic, Electrochim. Acta 53 (2008) 6076-6080.

[37] S. Brimaud, A.K. Engstfeld, O.B. Alves, H.E. Hoster, R.J. Behm, Top. Catal. 57 (2013) 222-235.

[38] M. Batzill, D.E. Beck, B.E. Koel, Surf. Sci. 466 (2000) L821-L826.

[39] U. Bardi, Reports Prog. Phys. 57 (1994) 939-987.

[40] C. Stampfl, S. Schwegmann, H. Over, M. Scheffler, G. Ertl, Phys. Rev. Lett. 77 (1996) 33713374.

[41] G.A. Somorjai, J.Y. Park, Surf. Sci. 603 (2009) 1293-1300.

[42] J.K. Nørskov, Rep. Prog. Phys. 53 (1990) 1253-1295.

[43] K.W. Kolasinski, Surface Science, Wiley \& Sons, Chichester, 2002.

[44] S. Lee, S. Mukerjee, E. Ticianelli, J. McBreen, Electrochim. Acta 44 (1999) 3283-3293.

[45] B.A. Peppley, J.C. Amphlett, R.F. Mann, in:, W. Vielstich, A. Lamm, H.A. Gasteiger (Eds.), Handb. Fuel Cells - Fundam. Technol. Appl. Vol. 3 Fuel Cells Technol., Wiley, Chichester, 2003, pp. 131-140.

[46] L. Carrette, K. A. Friedrich, U. Stimming, Fuel Cells 1 (2001) 5-39.

[47] A. Hamnett, in:, W. Vielstich, H.A. Gasteiger, A. Lamm (Eds.), Electrocatalysis, Wiley \& Sons, Chichester, 2003, pp. 305-322.

[48] A. Wieckowski, Interfacial Electrochemistry: Theory, Experiment, and Applications, CRC Press, 1999.

[49] N.M. Marković, T.J. Schmidt, B.N. Grgur, H.A. Gasteiger, R.J. Behm, P.N. Ross, J. Phys. Chem. B 103 (1999) 8568-8577.

[50] W. Schmickler, E. Santos, Interfacial Electrochemistry, Springer-Verlag Berlin Heidelberg, 2010.

[51] M.T.M. Koper, Fuel Cell Catalysis: A Surface Science Approach, Wiley\&Sons, Chichester, 2009.

[52] J. Inukai, D.A. Tryk, T. Abe, M. Wakisaka, H. Uchida, M. Watanabe, J. Am. Chem. Soc. 135 (2013) 1476-1490.

[53] S.R. Longwitz, J. Schnadt, E.K. Vestergaard, R.T. Vang, I. Stensgaard, H. Brune, F. Besenbacher, J. Phys. Chem. B 108 (2004) 14497-14502.

[54] I. Villegas, M.J. Weaver, J. Chem. Phys. 101 (1994) 1648. 
[55] M. Ø. Pedersen, M.-L. Bocquet, P. Sautet, E. Lægsgaard, I. Stensgaard, F. Besenbacher, Chem. Phys. Lett. 299 (1999) 403-409.

[56] A. Cuesta, A. Couto, A. Rincón, M.C. Pérez, A. López-Cudero, C. Gutiérrez, J. Electroanal. Chem. 579 (2005) 1-12.

[57] W. Akemann, K.A. Friedrich, U. Stimming, J. Chem. Phys. 113 (2000) 6864-6874.

[58] H. Baltruschat, S. Ernst, ChemPhysChem 12 (2011) 56-69.

[59] A. Lagutchev, G.Q. Lu, T. Takeshita, D.D. Dlott, A. Wieckowski, J. Chem. Phys. 125 (2006) 154705.

[60] J.S. McEwen, S.H. Payne, H.J. Kreuzer, M. Kinne, R. Denecke, H.P. Steinrück, Surf. Sci. 545 (2003) 47-69.

[61] B.N.J. Persson, M. Tushaus, A.M. Bradshaw, J. Chem. Phys. 92 (1990) 5034-5046.

[62] P.J. Feibelman, B. Hammer, J.K. Nørskov, F. Wagner, M. Scheffler, R. Stumpf, R. Watwe, J. Dumesic, J. Phys. Chem. B 105 (2001) 4018-4025.

[63] M.T.M. Koper, T.H.M. Housmans, C.G.M. Hermse, J. Electroanal. Chem. 607 (2007) 69-82.

[64] A. Cuesta, Surf. Sci. 572 (2004) 11-22.

[65] A. Rodes, R. Gomez, J.M. Feliu, M.J. Weaver, Langmuir 16 (2000) 811-816.

[66] Z. Jusys, J. Kaiser, R.J. Behm, Phys. Chem. Chem. Phys. 3 (2001) 4650-4660.

[67] C.T. Campbell, G. Ertl, H. Kuipers, J. Segner, J. Chem. Phys. 73 (1980) 5862-5873.

[68] J. Grunes, J. Zhu, M. Yang, G.A. Somorjai, Catal. Lett. 86 (2003) 157-161.

[69] K. Lenz, B. Poelsema, S.L. Bernasek, G. Comsa, Surf. Sci. 189 (1987) 431-437.

[70] P.L.J. Gunter, J.W. Niemantsverdriet, F.H. Ribeiro, G.A. Somorjai, Catal. Rev. Sci. Eng. 39 (1997) 77.

[71] J.S. McEwen, S. Payne, H. Kreuzer, M. Kinne, R. Denecke, H.P. Steinrück, Surf. Sci. 545 (2003) 47-69.

[72] B. Poelsema, R.L. Palmer, G. Comsa, Surf. Sci. 136 (1984) 1-14.

[73] J.A. Jensen, K.B. Rider, M. Salmeron, G.A. Somorjai, Phys. Rev. Lett. 80 (1998) 1228-1231.

[74] E. Kruse Vestergaard, P. Thostrup, T. An, E. Laegsgaard, I. Stensgaard, B. Hammer, F. Besenbacher, Phys. Rev. Lett. 88 (2002) 259601.

[75] N. Brønstedt, Chem. Rev. 5 (1928) 231-338.

[76] M.G. Evans, N.P. Polanyi, Trans.Faraday Soc. 34 (1938) 11-29.

[77] D. Zurawski, M. Wasberg, A. Wieckowski, J. Phys. Chem. 94 (1990) 2076-2082.

[78] R.L. Borup, D.E. Sauer, E.M. Stuve, Surf. Sci. 374 (1997) 142-150.

[79] H. Hoster, H. Gasteiger in: Handbook of Fuel Cells Vol. 2 (Electrocatalysis), W. Vielstich, A. Lamm, H.A. Gasteiger (eds.), John Wiley \& Sons, Chichester (2003) 237-265.

[80] K. Yoshimi, M.-B. Song, M. Ito, Surf. Sci. 368 (1996) 389-395.

[81] C. Lucas, N. Marković, P. Ross, Surf. Sci. 425 (1999) L381-L386.

[82] Y. Gründer, C.A. Lucas, this special issue

[83] J. Ye, Y. Jiang, T. Sheng, S. Sun, this special issue

[84] P. Malacrida, M. Escudero-Escribano, A. Verdaguer-Casadevall, I.E.L. Stephens, I. Chorkendorff, J. Mater. Chem. A 2 (2014) 4234. 
[85] R. Frydendal, E. A. Paoli, B.P. Knudsen, B. Wickman, P. Malacrida, I.E.L. Stephens, I. Chorkendorff, ChemElectroChem 2 (2014) 2075-2081.

[86] T.P. Johansson, E.T. Ulrikkeholm, P. Hernandez-Fernandez, P. Malacrida, H. A. Hansen, A. S. Bandarenka, J.K. Nørskov, J. Rossmeisl, I.E.L. Stephens, I. Chorkendorff, Top. Catal. 57 (2013) 245-254.

[87] T. Toda, H. Igarashi, M. Watanabe, J. Electroanal. Chem. 460 (1999) 258-262.

[88] H. Igarashi, T. Fujino, Y. Zhu, H. Uchida, M. Watanabe, Phys. Chem. Chem. Phys. 3 (2001) 306314.

[89] M. Wakisaka, S. Mitsui, Y. Hirose, K. Kawashima, H. Uchida, M. Watanabe, J. Phys. Chem. B 110 (2006) 23489-96.

[90] J.S. Spendelow, A. Wieckowski, ChemInform 36 (2005) 5094-5118.

[91] M. El-Jawad, J.-L. Chemin, B. Gilles, F. Maillard, Rev. Sci. Instrum. 84 (2013) 064101.

[92] T.P. Johansson, E.T. Ulrikkeholm, P. Hernandez-Fernandez, M. Escudero-Escribano, P. Malacrida, I.E.L. Stephens, I. Chorkendorff, Phys. Chem. Chem. Phys. 16 (2014) 13718-25.

[93] J. Greeley, I.E.L. Stephens, a S. Bondarenko, T.P. Johansson, H. A. Hansen, T.F. Jaramillo, J. Rossmeisl, I. Chorkendorff, J.K. Nørskov, Nat. Chem. 1 (2009) 552-556.

[94] Y. lijima, Y. Takahashi, K. Matsumoto, T. Hayashi, N. Todoroki, T. Wadayama, J. Electroanal. Chem. 685 (2012) 79-85.

[95] T.D. Jarvi, T.H. Madden, E.M. Stuve, Electrochem. Solid-State Lett. 2 (1999) 224-227.

[96] E. A. Carbonio, M.J. Prieto, A. De Siervo, R. Landers, J. Phys. Chem. C 118 (2014) 2867928688.

[97] M. El-Jawad, J.-L. Chemin, B. Gilles, F. Maillard, Rev. Sci. Instrum. 84 (2013) 064101.

[98] S. Brimaud, A.K. Engstfeld, O.B. Alves, R.J. Behm, J. Electroanal. Chem. 716 (2014) 71-79.

[99] H.E. Hoster, R.J. Behm, in:, M.T.M. Koper (Ed.), Fuel Cell Catal. A Surf. Sci. Approach, John Wiley \& Sons, Inc., Hoboken, NJ, USA, 2009, pp. 465-505.

[100] H. Baltruschat, J. Am. Soc. Mass Spectrom. 15 (2004) 1693-1706.

[101] J. Clavilier, R. Faure, G. Guinet, R. Durand, J. Electroanal. Chem. Interfacial Electrochem. 107 (1979) 205-209.

[102] E.L.D. Hebenstreit, W. Hebenstreit, M. Schmid, P. Varga, Surf. Sci. 441 (1999) 441-453.

[103] Y. Gauthier, M. Schmid, S. Padovani, E. Lundgren, V. Buš, G. Kresse, J. Redinger, P. Varga, Phys. Rev. Lett. 87 (2001) 36103-36106.

[104] K.J. Andersson, F. Calle-Vallejo, J. Rossmeisl, I. Chorkendorff, J. Am. Chem. Soc. 131 (2009) 2404-7.

[105] B.C. Han, A. Van der Ven, G. Ceder, B.-J. Hwang, Phys. Rev. B 72 (2005) 205409.

[106] H.A. Gasteiger, N.M. Markovic, P.N. Ross, Catal. Letters 36 (1996) 1-8.

[107] K. Wang, H.A. Gasteiger, N.M. Markovic, P.N. Ross, Electrochim. Acta 41 (1996) 2587-2593.

[108] W.C.A.N. Ceelen, A.W. Denier van der Gon, M.A. Reijme, H.H. Brongersma, I. Spolveri, A. Atrei, U. Bardi, Surf. Sci. 406 (1998) 264-278.

[109] S. Speller, U. Bardi, in:, D.P. Woodruff (Ed.), Chem. Phys. Solid Surfaces, Vol 10, Elsevier, Amsterdam, 2002, pp. 184-224.

[110] H.A. Gasteiger, N.M. Markovic, P.N. Ross, Catal. Letters 36 (1996) 1-8.

[111] M. Schmid, H. Stadler, P. Varga, Phys. Rev. Lett. 70 (1993) 1441-1444. 
[112] J. Kuntze, S. Speller, W. Heiland, A. Atrei, I. Spolveri, U. Bardi, Phys. Rev. B 59 (1999) R16005R16008.

[113] O. Petry, B. Podlovchenko, A. Frumkin, H. Lal, J. Electroanal. Chem. 10 (1965) 253-269.

[114] M. Watanabe, S. Motoo, J. Electroanal. Chem. 60 (1975) 275-283.

[115] H.A. Gasteiger, N.M. Markovic, P.N. Ross, J. Phys. Chem. 99 (1995) 16757-16767.

[116] H.A. Gasteiger, N. Markovic, P.N. Ross, E.J. Cairns, J. Phys. Chem. 98 (1994) 617-625.

[117] Y. Shimodaira, T. Tanaka, T. Miura, A. Kudo, H. Kobayashi, J. Phys. Chem. C 111 (2007) 272279.

[118] J.C. Davies, B.E. Hayden, D.J. Pegg, Electrochim. Acta 44 (1998) 1181-1190.

[119] A. Bergbreiter, A. Berkó, P. Erne, H. Hoster, R. Behm, Vacuum 84 (2009) 13-18.

[120] A. Bergbreiter, H.E. Hoster, R.J. Behm, ChemPhysChem 12 (2011) 1148-54.

[121] H. Hoster, A. Bergbreiter, P. Erne, T. Hager, H. Rauscher, R. Behm, Phys. Chem. Chem. Phys. 10 (2008) 3812-3823.

[122] F. Buatier de Mongeot, M. Scherer, B. Gleich, E. Kopatzki, R. Behm, Surf. Sci. 411 (1998) 249262.

[123] P. Jakob, A. Schlapka, Surf. Sci. 601 (2007) 3556-3568.

[124] H. Rauscher, T. Hager, T. Diemant, H. Hoster, F. Buatier de Mongeot, R.J. Behm, Surf. Sci. 601 (2007) 4608-4619.

[125] H.E. Hoster, M.J. Janik, M. Neurock, R.J. Behm, Phys. Chem. Chem. Phys. 12 (2010) 10388-97.

[126] T. Bligaard, J.K. Nørskov, S. Dahl, J. Matthiesen, C.H. Christensen, J. Sehested, J. Catal. 224 (2004) 206-217.

[127] B. Hammer, J. Norskov, Surf. Sci. 343 (1995) 211-220.

[128] M. Lischka, C. Mosch, A. Gross, Electrochim. Acta 52 (2007) 2219.

[129] M. Gsell, P. Jakob, D. Menzel, Science 280 (1998) 717-720.

[130] H. Pfnür, P. Feulner, D. Menzel, J. Chem. Phys. 79 (1983) 4613-4623.

[131] H.E. Hoster, in:, AIP Conf. Proc., 2012, pp. 9-14.

[132] G. Ertl, M. Neumann, K. Streit, Surf. Sci. 64 (1977) 393-410.

[133] S.R. Longwitz, J. Schnadt, E.K. Vestergaard, R.T. Vang, I. Stensgaard, H. Brune, F. Besenbacher, J. Phys. Chem. B 108 (2004) 14497-14502.

[134] G. Jerkiewicz, Prog. Surf. Sci. 57 (1998) 137-186.

[135] M.T.M. Koper, Faraday Discuss. 140 (2008) 11-24.

[136] G. Jerkiewicz, A. Zolfaghari, J. Electrochem. Soc. 143 (1996) 1240-1248.

[137] A. Zolfaghari, G. Jerkiewicz, J. Electroanal. Chem. 420 (1996) 11-15.

[138] A. Zolfaghari, G. Jerkiewicz, J. Electroanal. Chem. 467 (1999) 177-185.

[139] L.A. Kibler, A.M. El-Aziz, R. Hoyer, D.M. Kolb, Angew. Chemie Int. Ed. 44 (2005) 2080-2084.

[140] J. Greeley, J.K. Nørskov, L.A. Kibler, A.M. El-Aziz, D.M. Kolb, ChemPhysChem 7 (2006) 1032-5.

[141] J. Mostany, E. Herrero, J.M. Feliu, J. Lipkowski, J. Electroanal. Chem. 558 (2003) 19-24.

[142] A. Lasia, J. Electroanal. Chem. 562 (2004) 23-31.

[143] N. Garcia-Araez, V. Climent, J.M. Feliu, J. Solid State Electrochem. 12 (2007) 387-398.

[144] M.T.M. Koper, J.J. Lukkien, J. Electroanal. Chem. 485 (2000) 161-165. 
[145] G.S. Karlberg, T.F. Jaramillo, E. Skúlason, J. Rossmeisl, T. Bligaard, J.K. Nørskov, Phys. Rev. Lett. 99 (2007) 1-4.

[146] V. Climent, R. Gómez, J.M. Orts, J.M. Feliu, J. Phys. Chem. B 110 (2006) 11344-11351.

[147] M. Wakisaka, H. Suzuki, S. Mitsui, H. Uchida, M. Watanabe, Langmuir 25 (2009) 1897-900.

[148] T. Diemant, A. Bergbreiter, J. Bansmann, H.E. Hoster, R.J. Behm, ChemPhysChem 11 (2010) 3123-32.

[149] M. Watanabe, S. Motoo, J. Electroanal. Chem. 60 (1975) 267-273.

[150] H. Binder, A. Köhling, G. Sandstede, in:, G. Sandstede (Ed.), University of Washington Press for Batelle Seattle Research Center, Seattle, London, 1972, pp. 43-58.

[151] H.A. Gasteiger, N. Markovic, P.N. Ross, E.J. Cairns, J. Electrochem. Soc. 141 (1994) 1795-1803.

[152] E.A. Batista, H. Hoster, T. Iwasita, J. Electroanal. Chem. 554-555 (2003) 265-271.

[153] H.E. Hoster, T. Iwasita, H. Baumgärtner, W. Vielstich, J. Electrochem. Soc. 148 (2001) A496A501.

[154] G.-Q. Lu, J.O. White, A. Wieckowski, Surf. Sci. 564 (2004) 131-140.

[155] W.F. Lin, M.S. Zei, M. Eiswirth, G. Ertl, T. Iwasita, W. Vielstich, J. Phys. Chem. B 103 (1999) 6968-6977.

[156] K.A. Friedrich, K.-P. Geyzers, A. Marmann, U. Stimming, R. Vogel, Zeitschrift Für Phys. Chemie 208 (1999) 137-150.

[157] J.S. Spendelow, A. Wieckowski, Phys. Chem. Chem. Phys. 6 (2004) 5094-5118.

[158] W. Chrzanowski, A. Wieckowski, Langmuir 13 (1997) 5974.

[159] G. Tremiliosi-Filho, H. Kim, W. Chrzanowski, A. Wieckowski, B. Grzybowska, P. Kulesza, J. Electroanal. Chem. 467 (1999) 143-156.

[160] H. Inoue, S.R. Brankovic, J.X. Wang, R. Adzic, Electrochim. Acta 47 (2002) 3777-3785.

[161] S.R. Brankovic, J.X. Wang, R.R. Adzic, Surf. Sci. 474 (2001) L173-L179.

[162] S.R. Brankovic, N.S. Marinkovic, J.X. Wang, R.R. Adzic, J. Electroanal. Chem. 532 (2002) 57 66 .

[163] J.X. Wang, S.R. Brankovic, Y. Zhu, J.C. Hanson, R.R. Adzic, J. Electrochem. Soc. 150 (2005) A1108-A1117.

[164] S.R. Brankovic, J. McBreen, R.R. Adzic, J. Electroanal. Chem. 503 (2001) 99-104.

[165] H. Hoster, B. Richter, R. Behm, J. Phys. Chem. B 108 (2004) 14780-14788.

[166] A.V. Ruban, H.L. Skriver, J.K. Nørskov, in:, D.P. Woodruff (Ed.), Chem. Phys. Solid Surfaces, Vol 10, Elsevier, Amsterdam, 2002, pp. 1-29.

[167] A. Christensen, A. Ruban, P. Stoltze, K. Jacobsen, H. Skriver, J.K. Nørskov, F. Besenbacher, Phys. Rev. B 56 (1997) 5822-5834.

[168] H.E. Hoster, A. Bergbreiter, P.M. Erne, T. Hager, H. Rauscher, R.J. Behm, Phys. Chem. Chem. Phys. 10 (2008) 3812-23.

[169] B. Sadigh, M. Asta, V. Ozoliņ̌s, A. Schmid, N. Bartelt, A. Quong, R. Hwang, Phys. Rev. Lett. 83 (1999) 1379-1382.

[170] J.A. Stephens, H.C. Ham, G.S. Hwang, J. Phys. Chem. C 114 (2010) 21516-21523.

[171] A. Berkó, A. Bergbreiter, H.E. Hoster, R.J. Behm, Surf. Sci. 603 (2009) 2556-2563.

[172] H. Hartmann, T. Diemant, A. Bergbreiter, J. Bansmann, H.E. Hoster, R.J. Behm, Surf. Sci. 603 
(2009) 1439-1455.

[173] R. Rötter, Diplomarbeit (Thesis), Ulm University, 2009.

[174] A. Bergbreiter, O.B. Alves, H.E. Hoster, ChemPhysChem 11 (2010) 1505-12.

[175] A.K. Engstfeld, H.E. Hoster, R.J. Behm, Phys. Chem. Chem. Phys. 14 (2012) 10754.

[176] A.M. El-Aziz, L.A. Kibler, Electrochem. Commun. 4 (2002) 866-870.

[177] O.B. Alves, H.E. Hoster, R.J. Behm, Phys. Chem. Chem. Phys. 13 (2011) 6010-21.

[178] H.E. Hoster, R.J. Behm, in: M.T.M. Koper (Ed.), Fuel Cell Catalysis: a Surface Science Approach, Wiley\&Sons, Chichester, 2008, pp. 465-505.

[179] H.E. Hoster, M.J. Janik, M. Neurock, R.J. Behm, Phys. Chem. Chem. Phys. 12 (2010) 10388-97.

[180] T. Diemant,T. Hager,H.E. Hoster,H. Rauscher,R.J. Behm , Surface Science 541 (2003) 137-146.

[181] A.K. Engstfeld, S. Brimaud, R.J. Behm, Angew. Chem. Int. Ed. Engl. 53 (2014) 12936-40.

[182] A. K. Engstfeld, J. Klein, S. Brimaud, R.J. Behm, Surf. Sci. 631 (2014) 248-257.

[183] M. Pedersen, S. Helveg, A. Ruban, I. Stensgaard, E. Lægsgaard, J.K. Nørskov, F. Besenbacher, Surf. Sci. 426 (1999) 395-409.

[184] M. Arenz, A. Zana, this special issue

[185] N.S. Marinkovic, J.X. Wang, H. Zajonz, R.R. Adzic, J. Electroanal. Chem. 500 (2001) 388-394. 